This author accepted manuscript is deposited under a Creative Commons Attribution Non-commercial 4.0 International (CC BY-NC) licence. This means that anyone may distribute, adapt, and build upon the work for non-commercial purposes, subject to full attribution. If you wish to use this manuscript for commercial purposes, please contact permissions@emerald.com. 


\title{
Higher moments and US industry returns: Realized skewness and kurtosis
}

\begin{abstract}
Purpose - The purpose of this paper is to examine the relationships between the higher moments of returns (realized skewness and kurtosis) and subsequent returns at the industry level, with a focus on both empirical predictability and practical application via trading strategies.

Design/methodology/approach - Daily returns for 48 US industries over the period 19702019 from Kenneth French's data library are used to calculate the higher moments and to construct short- and medium-term single-sort trading strategies. The analysis adjusts returns for common risk factors (market, size, value, investment, profitability and illiquidity) to confirm whether conventional asset pricing models can capture these relationships.

Findings - Past skewness positively relates to subsequent industry returns and this relationship is unexplained by common risk factors. There is also a time-varying effect in that the predictive role of skewness is much stronger over business cycle expansions than recessions, a result consistent with varying investor optimism. However, there is no significant relationship between kurtosis and subsequent industry returns. The analysis confirms robustness using both value- and equal-weighted returns.
\end{abstract}

Research limitations/implications - The calculation of realized moments conventionally employs high-frequency intra-day data, regrettably unavailable for industries. In addition, the chosen portfolio-sorting method may omit some information as it compares only average group returns. Nonetheless, the close relationship between skewness and future returns at the industry level suggests variations in returns unexplained by common risk factors. This enriches knowledge of market anomalies and questions yet again weak-form market efficiency and the validity of conventional asset pricing models. One suggestion is that it is possible to significantly improve existing multi-factor asset pricing models by including industry skewness as a risk factor.

Practical implications - Given the relationship between skewness and future returns at the industry level, investors may predict subsequent industry returns to select better-performing funds. They may even construct trading strategies based on return distributions that would generate abnormal returns. Further, as the evaluation of individual stocks also contains industry information, and stocks in industries with better performance earn higher returns, risks related to industry return distributions can also shed light on individual stock picking. 
Originality - While there is abundant evidence of the relationships between higher moments and future returns at the firm level, there is little at the industry level. Further, by testing whether there is time variation in the relationship between industry higher moments and future returns, the paper yields novel evidence concerning the asymmetric effect of stock return predictability over business cycles. Lastly, the analysis supplements firm-level results focusing only on the decomposed components of higher moments.

Keywords Market anomalies, Industry returns, Higher moments, Skewness, Kurtosis Paper type Research Paper 


\section{Introduction}

The US stock market, the largest in the world, plays a major role in raising funds for companies and offering investment opportunities for global investors. The ultimate goal of nearly all of these investors is to gain high returns, so they seek techniques to predict future returns. In response, the finance mainstay of the efficient market hypothesis $(\mathrm{EMH})$ postulates that returns follow a random walk and cannot be predicted, while asset pricing models, including the capital asset pricing model (CAPM) (Lintner, 1965; Mossin, 1966; Sharpe, 1964) and the FamaFrench $(1993,2015)$ three- and five-factor models, endeavor to price these same returns.

However, so-called market anomalies (situations where investors earn abnormal returns not captured by these conventional models) challenge both the EMH and asset pricing models, bringing a ray of hope for investors in predicting future returns and thereby earning larger gains. Many studies propose "a zoo of new factors" (Cochrane, 2011) and market anomalies associated with past higher moments (skewness and kurtosis) receive much attention in predicting individual stock returns (Amaya et al., 2015; Bali et al., 2019; Conrad et al., 2013). Nonetheless, as industry performance contains crucial information about individual stocks (Kadan et al., 2012; Wu and Mazouz, 2016), and as industry funds are widely available investment vehicles (Wu, 2015), we need to extend the results for individual stock returns and investigate whether past higher moments also relate to future returns at the industry level.

Our first motivation for studying market anomalies associated with past higher moments is that these moments describe the risks of return movements, and are therefore primary factors for predicting future returns. Many studies argue that in addition to mean and volatility, skewness and kurtosis should also be included as risk factors in asset pricing, especially as returns are typically not normally distributed (Amaya et al., 2015; Bali et al., 2019; Conrad et al., 2013). A second motivation is the significant role of industry performance in real-world investment activity. From an empirical perspective, most studies consider return predictability at the firm level. However, when selecting profitable individual stocks, industry performance can shed light on predicting the subsequent returns of individual stocks (Wu and 
Mazouz, 2016). For example, some analysts believe that stocks in outperforming industries can generate higher returns (Kadan et al., 2012).

More importantly, as the returns of firms belonging to the same industry exhibit comovements, theoretical models argue that risks at the firm level are driven by industry characteristics (Bustamante, 2015; Wu and Mazouz, 2016) and empirical studies subsequently find that industry risks can indeed explain individual stock returns (Hameed and Mian, 2015; Wu and Mazouz, 2016). Consequently, instead of holding individual stocks, some investors may prefer investing in industry funds, such as sector mutual funds and exchange-traded funds. Currently, these are receiving much attention (Wu, 2015), especially as funds managed by professionals may obtain higher returns (Barber and Odean, 2011).

A third and final motivation is that stocks in the same industry or industries with similar characteristics, technology, and macroeconomic environments typically relate closely to each other, displaying comparable return distributions or return comovements (Jia and Yan, 2017; Parsons et al., 2020; Wu and Mazouz, 2016). Stocks in the same industry may also be subject to the same investor preferences, which may likewise determine return movements. Moreover, Zhang (2005) argues that moments measured using industry data are more accurate than those using individual data. This may be because industry moments capture common shocks or events that affect all the firms within the same industry (Wu and Mazouz, 2016).

Applying portfolio-sorting strategies to the monthly returns of 48 US industries, we find that realized skewness positively relates to subsequent industry returns and that this relationship is uncaptured by common risk factors. Interestingly, this relationship is much stronger over business cycle expansions than recessions, which is consistent with the optimistic attitudes of investors during upturns in economic activity (Blau, 2017; Byun and Kim, 2016). However, there is no significant relationship between kurtosis and subsequent industry returns. Our results are robust when calculating moments and future returns using either value- or equal-weighted industry daily returns.

Our study contributes to existing studies of asset pricing in three ways. First, while the relationships between higher moments and future returns at the firm level receive much 
attention, industry returns are scarcely considered. This is somewhat a mystery as it is well known that industry return distributions are equally or even more important when making investment decisions (Hameed and Mian, 2015; Kadan et al., 2012; Wu and Mazouz, 2016) and that sector funds are increasingly common, suggesting a critical role in asset pricing (Wu, 2015). By providing a useful return predictor in the form of realized skewness, we significantly extend our understanding of industry return distributions and industry investment. ${ }^{[1]}$

Second, recent studies find that many return predictors entail asymmetric effects over business cycle recessions and expansions (Andrei et al., 2019; Gregoriou et al., 2020; Racicot and Théoret, 2019). Although Gregoriou et al. (2020) and Racicot and Théoret (2019) consider the relationship between systematic higher moment risks contained in hedge funds and economic conditions, to our best knowledge none has considered the predictive role of industry higher moments over business cycles. Motivated by these results, we test the relationships between industry higher moments and returns over business cycles. The stronger predictive role of industry skewness over expansions found in our study further highlights the need to link economic conditions to industry return pricing in academia and to portfolio investments in the real world.

Finally, unlike many studies investigating the so-called "diversified" version of higher moments, namely, co-skewness and co-kurtosis (e.g., Back, 2014; Back et al., 2018; Gregoriou et al., 2020), we focus on total realized skewness and kurtosis. According to the EMH, it is possible to diversify idiosyncratic risks and price only systematic risks in an efficient market. However, many empirical studies argue that stock markets are not perfectly efficient and find that idiosyncratic skewness (kurtosis) significantly predicts future returns at the firm level (Bali et al., 2019; Boyer et al., 2010; Conrad et al., 2013). Rather than decomposing higher moments, our study investigates total skewness and kurtosis as they fit industry portfolios more appropriately. The results thus help us better understand industry return distributions and

\footnotetext{
${ }^{[1]}$ While Jia and Yan (2017) consider the relationship between skewness and momentum returns at both the firm and industry levels, we test whether industry higher moments can predict future industry returns, rather than industry momentum returns. Moreover, Jia and Yan (2017) only consider skewness, whereas we evaluate both skewness and kurtosis, in line with very early and more recent suggestions of the importance of their close relationship by Wilkins (1944) and Schopflocher and Sullivan (2005).
} 
supplement firm-level results that only focus on the decomposed components of higher moments. The realized measures used in our analysis also help reduce estimation errors contained in the prevailing model-dependent and option-related measures (Andersen and Benzoni, 2008; Yu, 2002).

The remainder of the paper is structured as follows. Section 2 reviews the related literature on higher moments and subsequent returns. Section 3 discusses the data and Section 4 illustrates the method, including the trading strategies and the calculation of the returns and moments. Section 5 presents the empirical results and Section 6 provides robustness tests. Section 7 concludes.

\section{Literature review}

For decades, asset pricing studies have sought to identify potential pricing factors to capture returns, with historical patterns and risks of return movements being the primary factors for predicting future returns (Amaya et al., 2015; Bali et al., 2019; Conrad et al., 2013). Many studies find that in addition to mean and volatility, investors also care about the higher moments of their holding portfolio returns (e.g., Back, 2014; Back et al., 2018; Gregoriou et al., 2020). This raises the issue of pricing higher moments.

Although skewness has long received empirical attention, the results concerning the relationship between skewness and subsequent returns remain mixed. On the one hand, and according to the EMH, we can diversify idiosyncratic risks and price only systematic risks in an efficient market. Given this phenomenon, studies employ dynamic methods to estimate the "diversified" version of skewness, being systematic skewness (or co-skewness) representing the sensitivity to the skewness of market portfolios and conclude a negative relationship between co-skewness and subsequent returns. For example, early work by Kraus and Litzenberger (1976) finds that unconditional co-skewness predicts the performance of the aggregate market portfolio and therefore should be included in the Lintner-Sharpe-Mossin CAPM. In contrast, Harvey and Siddique (2000) focus on conditional co-skewness and reveal a negative relationship with the future returns of both individual stocks and portfolios formed on dynamic criteria (e.g., industry, size and value). 
Alternatively, Langlois (2020) develops a novel method for predicting future skewness risk and obtain a significant risk premium earned on the predicted systematic skewness factor of buying (selling) low (high) co-skewness stocks. The negative relationship in these empirical studies is consistent with the theoretical model in Kraus and Litzenberger (1976) whereby investors prefer positive skewness but require higher expected returns for holding securities with negative co-skewness. Other studies challenge the EMH and argue that stock markets are not always efficient. For example, Boyer et al. (2010) obtain a negative relationship between expected idiosyncratic skewness and returns.

Most studies using another well-established skewness measure, namely, option-implied skewness, usually obtain opposing results. For instance, Rehman and Vilkov (2012) and Stilger et al. (2016) find that option-implied skewness positively relates to future realized returns, while Stilger et al. (2016) conclude that this relationship is driven by the idiosyncratic component of skewness. Bali et al. (2019) also consider the positive relationship between ex ante option-implied idiosyncratic skewness and price target-based expected stock returns, as explained by demand-based option pricing theory (Garleanu et al., 2009). In brief, informed investors prefer to buy (sell) calls (puts) when the underlying stocks are undervalued, and this pushes the call (put) price higher (lower), leading to a high right-tail probability associated with high skewness for stocks and higher expected returns.

Assuming that investors care about both systematic and unsystematic risk, some studies also investigate total skewness rather than decomposing the higher moments. For instance, Amaya et al. (2015) identify a negative relationship between high-frequency realized skewness and the following week's stock returns. Likewise, Zhang (2005) estimates intra-group crosssectional skewness and finds that a strategy of buying (selling) stocks with lower (higher) skewness could also earn excess returns.

Compared with skewness, there is rather less attention given to kurtosis in the literature. Under the EMH, very early work by Wilkins (1944) and later Schopflocher and Sullivan (2005) proves a U-shaped relationship between skewness and kurtosis. For this reason, as skewness is known to be priced in stock markets, kurtosis should also predict returns. For instance, Dittmar 
(2002) links diversified higher moments with investor behavior and finds that co-kurtosis provides better explanatory power than co-skewness for market returns. In contrast, Conrad et al. (2013) specify option-implied kurtosis and conclude that the idiosyncratic component drives the positive relationship between kurtosis and subsequent returns.

However, the predictive power of neither systematic nor idiosyncratic kurtosis is robust. Recent analysis by Bali et al. (2019) reveals that systematic option-implied kurtosis has no influence on return predictability at the firm level. Ayadi et al. (2019) also point out that idiosyncratic kurtosis is not priced in Fama-MacBeth (1973) regressions, although it does relate to stock returns in some subsample periods. Alternatively, Amaya et al. (2015) conclude a positive relationship between realized total kurtosis and the following week's returns, but find it is not always robust when using different measures of kurtosis. Similarly, Bai et al. (2016) suggest that kurtosis provides no incremental benefit in predicting future bond returns, especially after controlling for volatility and skewness.

The limits of these and other existing studies motivate our method in three ways. First, we consider the predictive role of industry not individual stock skewness and kurtosis. This enhances our understanding of industry return distributions and investments. Second, unlike existing studies, we evaluate the predictive power of industry higher moments over business cycles. This reveals the time-varying effect of the relationship between industry higher moments and future returns. Finally, many studies use the model-dependent approaches that rely on assumptions for parameters (Andersen and Benzoni, 2008; Yu, 2002) or the optionimplied measurement that requires assumptions to translate option-related moments to physical moments (Langlois, 2020). Our constructed realized skewness and kurtosis, however, are free from pre-determined assumptions. This has the added benefit in that unlike the "diversified" moments (co-skewness or co-kurtosis) in existing studies (e.g., Back, 2014; Back et al., 2018; Harvey and Siddique, 2000), realized skewness and kurtosis better fit industry portfolios as these are ordinarily undiversified. 


\section{Data}

We collect data on 48 industry returns in the US stock market and the risk-free rate of return proxied using the one-month US Treasury bill rate from the Kenneth French data library (French, 2020). The sample period is from January 1, 1970 to December 30, 2019. This is the longest period for which the returns of all US industries and common risk factors are available. As small stocks typically have low liquidity, most investors, especially US institutional investors, prefer large stocks (Gompers and Metrick, 2001). For this reason, we use valueweighted industry daily returns to calculate the moments and future returns. While other studies also use value-weighted returns (e.g., Dichev, and Yu, 2011; Fama et al., 1993; Nyberg and Vaihekoski, 2010), in Section 6 we check for the robustness of our results using equal-weighted daily industry returns.

Table I provides summary statistics of the monthly returns of the 48 industries, including the four moments (mean, volatility, skewness, and kurtosis) along with the statistics for Jarque-Bera normality tests of monthly industry returns and average monthly excess returns. We use realized measures here as the trading strategies constructed later employ realized moments. Overall, the average monthly returns from 1970 to 2019 are all positive, and most industries perform better than the risk-free asset save Coal, Real Estate, and Others.

\section{$<$ INSERT TABLE I HERE $>$}

Setting the mean return as zero, realized skewness measures the degree of distortion from the normal distribution around zero. Table I reveals that most industries have negative skewness, indicating that the distributions of their monthly returns have long tails extending to the left. For its part, kurtosis represents the degree of peakedness in a distribution. All the industry distributions exhibit a value of kurtosis greater than three, indicating the greater likelihood of more extreme returns, either negative or positive. The negative skewness, high kurtosis and significant Jarque-Bera statistics suggest that these monthly industry returns are not normally distributed. We also examine whether common risk factors (market, size, value, investment, profitability and illiquidity) can help explain the predictive power of moments. We 
obtain the market, size, value, investment and profitability factors from the Kenneth French data library (French, 2020) and the illiquidity factor from Pastor (2020).

\section{Method}

Our objective is to investigate whether industry skewness (kurtosis) predicts future returns over multiple trading horizons in the US stock market, for which we employ the following testable hypotheses. The null hypothesis is that realized skewness (kurtosis) is unrelated to subsequent returns at the industry level over the short or medium term. As many studies identify the predictive power of higher moments at the firm level (Amaya et al., 2015; Bali et al., 2019; Stilger et al., 2016), we expect to reject the null. However, the expected signs of the relationships are empirically unknown.

To test the relationship between industry higher moments and future returns, we first gather industry returns over the sample period and calculate realized skewness and kurtosis for each industry over different estimation periods. We then construct trading strategies over selected periods to test our hypotheses. We then adjust the holding-period returns using the CAPM, Fama-French three- and five-factor models, and the constructed six-factor model, and conclude that if these relationships remain significant, the moments additionally predict future returns at the industry level after adjusting for common risk factors.

\subsection{Trading strategies}

Following Amaya et al. (2015), we employ a single-sort strategy to evaluate the relationships between moments and future returns. Taking trading strategies with skewness as an example, at each beginning month $t$, industries are ranked in ascending order based on their past realized skewness over an $E$-month estimation period $(E=1,3,6,9,12,24)$. A zero-cost portfolio of buying (selling) the highest- (lowest-) skewness group is formed, and then each portfolio is held over the next $H$-month holding period $(H=1,3,6,9,12,24)$ to obtain the holding-period portfolio returns. This strategy is then repeated at the beginning of month $t+1$ and so on. Finally, we adjust the holding-period returns using conventional asset pricing models 
to further check whether the relationship between higher moments and future returns at the industry level is explained by common risk factors.

When generating average monthly returns over the holding periods, we calculate equalweighted monthly raw returns. Although many studies of individual stock returns calculate both equal- and value-weighted portfolio returns, this is not possible with industry given the unavailability of the market size by industry data in this study.

\subsection{Calculations}

\section{$\underline{\text { Estimation-period moments }}$}

We transform the raw industry returns sourced from the Kenneth French Data Library to continuously compounded $(\log )$ returns, as below:

$$
\mathrm{r}_{t, i}=\ln \left(1+\frac{x_{i, t}}{100}\right)
$$

where $x$ is the daily raw return for industry $i$ at day $t$ multiplied by 100 and $r_{t, i}$ are the daily natural $\log$ returns. ${ }^{[2]}$ We measure total skewness and kurtosis in undiversified industry portfolios. As discussed, for skewness, we use realized skewness, being a model-free approach that reduces estimation errors (Andersen and Benzoni, 2008; Yu, 2002). While it is commonplace for studies to employ intra-day high frequency realized skewness when considering the higher moments of individual stocks, it is difficult to obtain this information by industry. That said, high frequency realized moments are also excessively noisy, so monthly realized moments are normally used when high-frequency data is not available (Chauvet et al., 2015; Eriksson et al., 2019; Yu, 2002). Following this same logic for monthly realized and quarterly realized moments, we expand this to estimation-period realized higher moments.

Following Amaya et al. (2015), the estimation-period skewness and kurtosis are:

$$
\begin{aligned}
\operatorname{RSkew}_{T, i} & =\frac{\sqrt{N} \sum_{t=1}^{N} r_{t, i}^{3}}{R \operatorname{Var} r_{T}^{3 / 2}}, \\
\operatorname{RKurt}_{T, i} & =\frac{N \sum_{t=1}^{N} r_{t, i}^{4}}{\operatorname{RVar} r_{T}^{2}} .
\end{aligned}
$$

\footnotetext{
${ }^{[2]}$ It is common to measure stock returns and the changes in other financial variables in their natural logarithmic form, especially when the returns and changes are not normally distributed (e.g., Diaz and de Gracia, 2017; Hudson and Gregoriou, 2015; Khan et al., 2019). In addition, log returns have the advantage of being addable when calculating holding-period returns over multiple trading horizons (Hudson and Gregoriou, 2015). Palazzo (2009) and Baur and Löffler (2015) that use the data in the Kenneth French Data Library also transform raw to logarithmic returns.
} 
where $r_{t, i}$ is the daily return (1) for each industry $i$ on trading day $t$ and $N$ is the number of observations in the estimation period $T . R \operatorname{Var}_{T}$ is the estimation-period realized variance, written as:

$$
\operatorname{RVar}_{T, i}=\sum_{t=1}^{N} r_{t, i}^{2}
$$

\section{Holding-period raw returns}

We measure holding-period zero-cost portfolio returns by using the average monthly excess returns over that holding period. The average monthly returns over holding periods are as below:

$$
R_{i, T}=\frac{1}{T} \sum_{t=1}^{N} \mathrm{r}_{t, i}
$$

where $R_{i, T}$ is the monthly average return of the zero-cost portfolio $i$ over a holding-period $T$ and $\mathrm{r}_{t, i}$ is the daily return for the zero-cost portfolio $i$ at day $t . N$ is the number of trading days and $T$ is the number of months in that holding period.

\section{Holding-period adjusted returns}

We also adjust the holding-period raw returns for common risk factors. If the relationships between moments and future returns remain (statistically) significant, moments may predict future returns at the industry level.

First, we apply the Lintner-Sharpe-Mossin CAPM to adjust returns. The CAPM is:

$$
R_{i, T}-R_{f, T}=\alpha_{i}+\beta_{i}\left(R_{m, T}-R_{f, T}\right)+\varepsilon_{i, T},
$$

where $R_{i, T}-R_{f, T}$ is the monthly excess return of zero-cost portfolio $i$ at holding period $T$. $R_{m, T}-R_{f, T}$ is the excess market return and $\beta_{i}$ represents how the return of industry $i$ changes with the level of market excess return.

Second, due to the poor empirical performance of the CAPM, Fama and French (1992, 1993) extend it to their three-factor model by adding size and value factors. The three-factor model is:

$$
R_{i, T}-R_{f, T}=\alpha_{i}+\beta_{i}\left(R_{m, T}-R_{f, T}\right)+s_{i} S M B_{T}+h_{i} H M L_{T}+\varepsilon_{i, T}
$$


where $S M B_{T}$ is the monthly average return on small-size portfolios minus that on big-size portfolios over a holding-period $T$, and $s_{i}$ captures how the size factor influences the excess return. $H M L_{T}$ is the average return on high book-to-market portfolios minus that on low bookto-market portfolios, and $h_{i}$ represents the risk related to this factor.

Third, although the three-factor model remains widely used, it still cannot capture some market anomalies and Fama and French (2015) extend it into a five-factor model by further including profitability and investment factors. The five-factor model is:

$$
R_{i, T}-R_{f, T}=\alpha_{i}+\beta_{i}\left(R_{m, T}-R_{f, T}\right)+s_{i} S M B_{T}+h_{i} H M L_{T}+r_{i} R M W_{T}+c_{i} C M A_{T}+\varepsilon_{i, T},
$$

where $R M W_{T}$ is the monthly average return difference between portfolios with strong profitability and those with weak profitability over holding period $T$, and $C M A_{T}$ is the return difference between portfolios with low and high investment ratios.

Finally, in addition to Fama and French's traditional factors, liquidity is also widely used in asset-pricing models (Pastor and Stambaugh, 2003, 2019; Racicot et al., 2018). More importantly, Stilger et al. (2016) find that the underperformance of illiquid stocks with lowest skewness partially explains the predictive power of risk-neutral skewness for individual stock returns. Following Racicot et al. (2018), we extend the Fama-French five-factor model by adding an illiquidity factor for buying (selling) stocks with high (low) liquidity betas as constructed by Pastor and Stambaugh $(2003,2019) .{ }^{[3]}$ The six-factor model is:

$$
\begin{array}{r}
R_{i, T}-R_{f, T}=\alpha_{i}+\beta_{i}\left(R_{m, T}-R_{f, T}\right)+s_{i} S M B_{T}+h_{i} H M L_{T}+r_{i} R M W_{T}+c_{i} C M A_{T} \\
+i_{i} L I Q_{T}+\varepsilon_{i, T},(9)
\end{array}
$$

where $L I Q_{T}$ is the monthly average returns of a mimicking portfolio of buying (selling) illiquid (liquid) stocks over holding period $T$.

\footnotetext{
${ }^{[3]}$ Pastor and Stambaugh $(2003,2019)$ and Amihud $(2002,2019)$ also use other measurements for constructing liquidity indicators. However, it will be difficult to interpret the alpha in an asset pricing model when using these alternative liquidity factors to construct models. So, we add the traded illiquidity factor that is comparable to Fama-French factors in the six-factor model.
} 


\section{Empirical results}

\subsection{Realized skewness and returns}

Table II provides the results of the single-sort trading strategies using past realized skewness calculated on value-weighted industry daily returns. As shown, the excess returns of the zero-cost portfolios are positive and significant over the $1 / 12,3 / 9,3 / 12,6 / 9,6 / 12,9 / 6,9 / 9$, $9 / 12,12 / 3,12 / 6,12 / 9$, and 12/12 trading horizons. The largest high-minus-low return is on the $12 / 3$ trading strategy, with a $0.383 \%$ excess return and a $t$-statistic of 2.12 , being statistically significant at the 5\% level. This return is also economically significant, with an annualized return of $4.596 \%(=0.383 \% \times 12)$. The positive relationship found in our study is consistent with these found in Bali et al. (2019), Langlois (2020), and Stilger et al. (2016).

\section{$<$ INSERT TABLE II HERE $>$}

Table III details the realized skewness results for the adjusted returns of the zero-cost portfolios. Newey and West (1987) adjusted $t$-statistics with six lags used are in parentheses. As shown, strategies that earn significant raw returns also show significant abnormal returns with large $t$-statistics. This indicates that the positive relationship between realized skewness and future industry returns is uncaptured by common risk factors. Compared with the raw results shown in Table II, abnormal returns become highly significant over more trading horizons. Many $t$-statistics are even greater than three, the high critical value suggested by Harvey et al. (2016) to reduce data mining issues. These results suggest a stronger positive relationship between realized skewness and adjusted industry returns. Stronger abnormal returns found in our study are consistent with the results of Conrad et al. (2013) and Stilger et al. (2016).

\section{$<$ INSERT TABLE III HERE $>$}

Based on these findings, we reject the null hypothesis that realized skewness is unrelated to subsequent returns at the industry level. One possible explanation is the poor performance of the low-skewness securities. Harvey and Siddique (2000) find that most 
investors prefer lottery-like assets with positive skewness. Because of this preference for positive skewness, industries with low (high) skewness are normally undervalued (overvalued). With the entrance of arbitrageurs, we expect the prices of the undervalued low-skewness industries to increase. However, over short- and medium-term holding periods, prices of lowskewness industries may remain at a low level rather than increasing dramatically because of the slow price correction mechanism, resulting in low returns (Rehman and Vilkov, 2012).

This slow price correction mechanism may derive from the illiquidity of the undervalued low-skewness industries (Stilger et al., 2016). Investors here may find it difficult to sell low-skewness industries due to the high-skewness preference (Harvey and Siddique, 2000). Therefore, Table II reveals that low-skewness industries will still exhibit low future returns over the short to medium term. We also test the exposure of the lowest-skewness industries to illiquidity risk. To do so, we regress the holding-period returns of the lowestskewness group on the traded illiquidity factor constructed by Pastor and Stambaugh (2003, 2019) and on a control variable (excess market return) over trading horizons earning significant zero-cost portfolio raw returns on past skewness. In the results (not shown), we find that the estimated coefficients on illiquidity are positive over the selected trading strategies. These results indicate that illiquidity risk exposes the lowest-skewness industries, and this may result in a slow price correction mechanism and the poor performance of these lowest-skewness industries.

The slow price correction process may also be due to a persistent preference for skewness. Back et al. (2018) conclude that many funds and portfolios do not earn positive abnormal returns after controlling for co-skewness. This indicates that most investors or fund managers show persistent demand for high-skewness securities and do not sacrifice favorable (positive) skewness to seek higher adjusted returns (Duarte et al., 2007). This persistent demand for high-skewness securities necessarily leads to a slow price correction mechanism in the market. 


\subsection{Realized kurtosis and returns}

Table IV details the results for realized kurtosis calculated on value-weighted industry daily returns. Overall, all raw excess returns of the zero-cost portfolios based on realized kurtosis are insignificant. After applying conventional asset pricing models to adjust these raw returns, we find that abnormal returns are also insignificant over dynamic horizons. These insignificant adjusted results are not reported for brevity but are available upon request. These raw and adjusted results together suggest that there is no relationship between kurtosis and future industry returns in the US. Our finding is consistent with Ayadi et al. (2019) and Bali et al. (2019).

\section{$<$ INSERT TABLE IV HERE $>$}

We explain these insignificant returns earned on the spread of kurtosis using the tradeoff between skewness and kurtosis. As the Wilkins' (1944) lower bound shows that kurtosis $\geq 1+$ skewness $^{2}$ and Schopflocher and Sullivan (2005) document that kurtosis $=\hat{A}+\left(\hat{B} \times\right.$ skewness $\left.^{2}\right)$ for turbulent distributions, there should be a U-shaped relationship between skewness and kurtosis, whereby both large positive and negative skewness will lead to high kurtosis. Based on this relationship, the highest-kurtosis group should contain industries with both high (largely positive) or low (largely negative) skewness and the average skewness for the highest-kurtosis group will then be either small or close to zero, while the lowest-kurtosis group should contain industries with near-zero skewness.

Table IV also reports the average skewness for each ranked kurtosis group. Consistent with the trade-off between skewness and kurtosis suggested by Wilkins (1944) and Schopflocher and Sullivan (2005), the average skewness for the highest- and lowest-kurtosis groups and the spreads of skewness between these ranked kurtosis groups are all smaller than the average skewness ranked in Table II. This small skewness spread should therefore lead to insignificant returns on the high-minus-low kurtosis portfolios. 


\subsection{Realized moments and returns over business cycles}

Many studies find that stock return predictability is sensitive to business cycles, as the variation in economic conditions will influence investor behavior and will eventually drive stock returns (Andrei et al., 2019; Racicot and Théoret, 2019; Wen and Li, 2020). Moreover, the relationship between higher moments contained in hedge funds and future returns has an asymmetric effect over the business cycles (Gregoriou et al., 2020; Racicot and Théoret, 2019).

Motivated by these findings, we further investigate whether the full-sample results found in the previous subsections are robust over business cycles. We apply a sub-sample analysis by constructing the zero-cost portfolios formed on the spread of the past-realized skewness (kurtosis) in business cycle expansions and recessions respectively. The Organization of Economic Development's (OECD) US recession indicators from the Federal Reserve Bank of St. Louis (2020) determine the economic condition for each portfolio-construction month, taking the form of a dummy variable with a value of one in recessionary months and zero elsewhere.

Table $\mathrm{V}$ details the returns of the ranking portfolios with the lowest and highest skewness and these of the zero-cost portfolio with $t$-statistics over expansions and recessions. Compared with the full-sample results ignoring economic conditions shown in Table II, more trading horizons earn significant returns on the spread of skewness in business cycle expansions. However, the relationship between realized skewness and future industry returns is insignificant when constructing trading strategies in recessionary months.

\section{$<$ INSERT TABLE V $>$}

Interestingly, Table $\mathrm{V}$ shows that the skewness spread in expansions is larger than that in recessions, except for the trading strategies over the 24-month estimation period. Moreover, the lowest-skewness portfolios exhibit even less skewness in expansions than recessions and as a result earn even lower future returns when constructing trading strategies in expansions than in recessions over most trading horizons. These larger spreads of skewness and the poorer performance of the low-skewness industries may help explain the stronger predictive role of 
skewness in expansions found elsewhere. Blau (2017) and Byun and Kim (2016) argue that investors are more optimistic during business cycle expansions and they are then likely to seek more lottery-like assets in their investments. Therefore, high- (low-) skewness securities will be overpriced (underpriced) more in expansions than in recessions. As discussed in Subsection 5.1, the prices of these overpriced (underpriced) securities will remain at a high (low) level due to a possible slow price correction mechanism.

Table VI displays the adjusted returns of the high-minus-low skewness portfolios constructed during expansions. Overall, strategies constructed during expansions that earn significant raw returns exhibit significant abnormal returns with large $t$-statistics. This indicates that the stronger relationship between realized skewness and future industry returns over expansions is unexplained by common risk factors. We also check the adjusted results of the strategies constructed in recessions and find insignificant abnormal returns over dynamic trading horizons. These insignificant results are unreported for brevity but are available upon request. Lastly, in an unreported analysis, we find no relationship between kurtosis and future industry returns during either recessions or expansions. This is consistent with the full-sample results shown in Table IV.

\section{$<$ INSERT TABLE VI $>$}

\section{Robustness check}

We use value-weighted industry daily returns to calculate moments and holding-period returns in Section 5. In this section, we further check whether our results remain robust when calculating moments and future returns by using equal-weighted industry daily returns. Table VII reports the results using equal-weighted daily returns for realized skewness. Overall, both raw and adjusted returns earned on the spread of skewness calculated on equal-weighted returns are significant over more trading horizons than these calculated on value-weighted returns as shown in Table II and Table III. Raw or adjusted returns earned on the spread of skewness calculated on equal-weighted returns are also much stronger than these calculated on valueweighted returns over most trading horizons. 


\section{$<$ INSERT TABLE VII $>$}

These stronger results using equal-weighted daily returns suggest that equal-weighted industry returns are more sensitive to skewness risks, which is consistent with Plyakha et al.'s (2014) argument concerning the exposure of equal-weighted returns to systematic risks. As large firms dominate value-weighted returns, our results also indicate that small stocks are more subject to industry skewness risk. Zaremba (2016) finds that small stocks are more sensitive to risks and earn higher abnormal returns than large stocks, as small stocks are normally thinly traded and are easily mispriced (Sadka, 2006). Consistent with the value-weighted return results, kurtosis calculated using equal-weighted daily returns is unrelated to future industry returns over dynamic trading windows (results not shown).

\section{Concluding remarks}

Many existing studies have confirmed the relationships between moments and subsequent returns at the firm level (Amaya et al., 2015; Bali et al., 2019; Conrad et al., 2013). As industry performance contains crucial information for individual stock investments (Kadan et al., 2012), and as industry funds are prevalent investment vehicles in the stock market (Wu, 2015), we considered these same relationships at the industry level in the US stock market.

Our findings indicate that realized skewness positively relates to subsequent industry returns. This relationship is unexplained by common risk factors, including market, size, value, profitability, investment, and illiquidity. We argue that the poor performance of low-skewness industries and a slow price correction mechanism might explain these results. We also find that the predictive role of skewness is much stronger over business cycle expansions than recessions. This result is consistent with the optimistic attitudes of investors in expansions (Blau, 2017; Byun and Kim, 2016). However, there is no significant relationship between kurtosis and subsequent industry returns. Our results are robust when calculating moments and future returns by using either value- or equal-weighted industry daily returns.

Taken together, these findings provide useful implications for both the theoretical and empirical literature and practical investor behavior. First, our findings enrich our knowledge of 
market anomalies and allow us to question yet again the validity of the EMH and the conventional asset pricing models. One possibility is to improve existing asset pricing models by including industry skewness as an additional risk factor in the spirit of Fama and French $(1993,2015)$. Further, while we only address industry returns, we can infer that the results may also shed light on the pricing of individual stocks as industry return movements also contain information about individual stock return variance (Kadan et al., 2012).

As discussed, the findings also suggest practical real-world trading strategies. Based on the relationship between skewness and future returns at the industry level, investors may predict subsequent industry returns to pick better-performing sector funds. They may even construct trading strategies based on return distributions that would generate abnormal returns. For example, as skewness positively relates to future industry returns, investors may buy past high skewness industries to earn higher future returns. Since the evaluation of individual stocks also contains industry information and stocks in industries with better performance earn higher returns, the information of risks related to industry return distributions can shed light on picking the right stocks (Wu and Mazouz, 2016). Investors may forecast profitable industries and then choose stocks within these industries to gain higher returns.

Of course, our analysis is not without its limitations. First, the literature normally uses high-frequency intra-day data to calculate realized moments. Unfortunately, this data is generally unavailable for industry portfolios. As a possible solution, future studies could collect high-frequency individual stock returns from the Trade and Quote (TAQ) database and then construct industry portfolio data. Second, our chosen portfolio-sorting method may omit some information as it compares only the average returns between the top and bottom groups. Future studies could then consider model-dependent methods (e.g., Fama-MacBeth (1973) regressions) and again use moments to price returns at the industry level.

\section{Acknowledgment:}

The authors would like to thank anonymous reviewers and the editor for their helpful comments and suggestions. 


\section{References}

Amaya, D., Christonerson, B., Jacobs, K., and Vasquez, A. (2015), "Does realized skewness predict the crosssection of equity returns?", Journal of Financial Economics, Vol. 118, No. 1, pp. 135-167.

Amihud, Y. (2002), "Illiquidity and stock returns: cross-section and time-series effects", Journal of Financial Markets, Vol. 5, No. 1, pp. 31-56.

Amihud, Y. (2019), "Illiquidity and stock returns: a revisit", Critical Finance Review, Vol. 8, pp. 203-221.

Andersen, T. G., and Benzoni, L. (2008), "Realized volatility”, working Paper, Federal Reserve Bank of Chicago.

Andrei, D., Carlin, B., and Hasler, M. (2019), "Asset pricing with disagreement and uncertainty about the length of business cycles”, Management Science, Vol. 65, No. 6, pp. 2900-2923.

Ayadi, M. A., Cao, X., Lazrak, S., and Wang, Y. (2019), "Do idiosyncratic skewness and kurtosis really matter?", The North American Journal of Economics and Finance, Vol. 50, pp. 101008.

Back, K. (2014), “A characterization of the coskewness-cokurtosis pricing model”, Economics Letters, Vol. 125, No. 2, pp. 219-222.

Back, K., Crane, A. D., and Crotty, K. (2018), "Skewness consequences of seeking alpha", The Review of Financial Studies, Vol. 31, No. 12, pp. 4720-4761.

Bai, J., Bali, T. G, and Wen, Q. (2016), "Do the distributional characteristics of corporate bonds predict their future returns?", working paper, Georgetown McDonough School of Business.

Bali, T. G., Hu, J., and Murray, S. (2019), "Option implied volatility, skewness, and kurtosis and the cross-section of expected stock returns", working paper, Georgetown McDonough School of Business.

Barber, B. M., and Odean, T. (2011), "The behavior of individual investors", working paper, London Business School.

Baur, D. G., and Löffler, G. (2015), "Predicting the equity premium with the demand for gold coins and bars", Finance Research Letters, Vol. 13, pp. 172-178.

Blau, B. M. (2017), "Skewness preferences, asset prices and investor sentiment", Applied Economics, Vol. 49, No. 8, pp. 812-822.

Boyer, B., Mitton, T., and Vorkink, K. (2010), "Expected idiosyncratic skewness", The Review of Financial Studies, Vol. 23, No. 1, pp. 169-202.

Bustamante, M. C. (2015), "Strategic investment and industry risk dynamics", The Review of Financial Studies, Vol. 28, No. 2, pp. 297-341.

Byun, S. J., and Kim, D. H. (2016), "Gambling preference and individual equity option returns", Journal of Financial Economics, Vol. 122, No. 1, pp. 155-174.

Chauvet, M., Senyuz, Z., and Yoldas, E. (2015), "What does financial volatility tell us about macroeconomic fluctuations?", Journal of Economic Dynamics and Control, Vol. 52, pp. 340-360.

Cochrane, J. H. (2011), "Presidential address: discount rates", The Journal of Finance, Vol. 66, No. 4, pp. 10471108.

Conrad, J., Dittmar, R.F., and Ghysels, E. (2013), “Ex ante skewness and expected stock returns”, The Journal of Finance, Vol. 68, No. 1, pp. 85-124.

Diaz, E. M., and de Gracia, F. P. (2017), “Oil price shocks and stock returns of oil and gas corporations”, Finance Research Letters, Vol. 20, pp. 75-80.

Dichev, I. D., and Yu, G. (2011), "Higher risk, lower returns: what hedge fund investors really earn", Journal of Financial Economics, Vol. 100, No. 2, pp. 248-263. 
Dittmar, R. F. (2002), "Nonlinear pricing kernels, kurtosis preference, and evidence from the cross section of equity returns", The Journal of Finance, Vol. 57, No. 1, pp. 369-403.

Duarte, J., Longstaff, F. A., and Yu, F. (2007), "Risk and return in fixed-income arbitrage: nickels in front of a steamroller?", The Review of Financial Studies, Vol. 20, No. 3, pp. 769-811.

Eriksson, A., Preve, D., and Yu, J. (2019), "Forecasting realized volatility using a nonnegative semiparametric model”, Journal of Risk and Financial Management, Vol. 12, No. 3, p. 139.

Fama, E. F., and French, K. R. (1992), “The cross-section of expected stock returns”, The Journal of Finance, Vol. 47, No. 2, pp. 427-465.

Fama, E. F., and French, K. R. (1993), “Common risk factors in the returns on stocks and bonds”, Journal of Financial Economics, Vol. 33, No. 1, pp. 3-56.

Fama, E. F., and French, K. R. (2015), “A five-factor asset pricing model”, Journal of Financial Economics, Vol. 116, No. 1, pp. 1-22.

Fama, E. F., and MacBeth, J. D. (1973), "Risk, return, and equilibrium: empirical tests", Journal of Political Economy, Vol.81, No. 3, pp. 607-636.

Fama, E. F., French, K. R., Booth, D. G., and Sinquefield, R. (1993), "Differences in the risks and returns of NYSE and NASD stock”, Financial Analysts Journal, Vol. 49, No. 1, pp. 37-41.

Federal Reserve Bank of St. Louis (2020). OECD based recession indicators for the United States from the period following the peak through the trough (USAREC), available at: https://fred.stlouisfed.org/series/USARECM (accessed 28 September 2020)

French, K. R. (2020), Current Research Returns, U.S. Research Returns Data, available at: https://mba.tuck.dartmouth.edu/pages/faculty/ken.french/data_library.html (accessed 28 September 2020)

Garleanu, N., Pedersen, L. H., and Poteshman, A. M. (2009), "Demand-based option pricing”, The Review of Financial Studies, Vol. 22, No. 10, pp. 4259-4299.

Gompers, P. A., and Metrick, A. (2001), "Institutional investors and equity prices", The Quarterly Journal of Economics, Vol. 116, No. 1, pp. 229-259.

Gregoriou, G. N., Racicot, F. É., and Théoret, R. (2020), “The response of hedge fund tail risk to macroeconomic shocks: A nonlinear VAR approach”, Forthcoming in Economic Modelling.

Hameed, A., and Mian, G. M. (2015), "Industries and stock return reversals", Journal of Financial and Quantitative Analysis, Vol. 50, No. 1/2, pp. 89-117.

Harvey, C. R., and Siddique, A. (2000), "Conditional skewness in asset pricing tests", The Journal of Finance, Vol. 55, No. 3, pp. 1263-1295.

Harvey, C. R., Liu, Y., and Zhu, H. (2016), “... and the cross-section of expected returns”, The Review of Financial Studies, Vol. 29, No. 1, pp. 5-68.

Hudson, R. S., and Gregoriou, A. (2015), "Calculating and comparing security returns is harder than you think: a comparison between logarithmic and simple returns", International Review of Financial Analysis, Vol. 38, pp. $151-162$

Jia, Y., and Yan, S. (2017), "Skewness and momentum", working paper, Central University of Finance and Economics (CUFE)-Chinese Academy of Finance and Development.

Kadan, O., Madureira, L., Wang, R., and Zach, T. (2012), “Analysts' industry expertise”, Journal of Accounting and Economics, Vol. 54, No. 2-3, pp. 95-120.

Khan, M. K., Teng, J. Z., and Khan, M. I. (2019), “Asymmetric impact of oil prices on stock returns in Shanghai stock exchange: evidence from asymmetric ARDL model”, PloS one, Vol. 14, No. 6, e0218289. 
Kraus, A., and Litzenberger, R. H. (1976), "Skewness preference and the valuation of risk assets", The Journal of Finance, Vol. 31, No. 4, pp. 1085-1100.

Langlois, H. (2020), "Measuring skewness premia”, Journal of Financial Economics, Vol. 135, No. 2, pp. 399424.

Lintner, J. (1965), "The valuation of risk assets and the selection of risky investments in stock portfolios and capital budgets", The Review of Economics and Statistics, Vol. 47, No. 1, pp. 13-37.

Mossin, J. (1966), "Equilibrium in a capital asset market", Econometric, Vol. 34, No. 4, pp. 768-783.

Newey, W. K., and West, K. D. (1987), "A Simple, positive semi-definite, heteroskedasticity and autocorrelation consistent covariance matrix", Econometrica, Vol. 55, No. 3, pp. 703-708.

Nyberg, P., and Vaihekoski, M. (2010), "A new value-weighted total return index for the Finnish stock market", Research in International Business and Finance, Vol. 24, No. 3, pp. 267-283.

Palazzo, B. (2009), "Firms' cash holdings and the cross-section of equity returns", working paper, New York University.

Parsons, C. A., Sabbatucci, R., and Titman, S. (2020), "Geographic lead-lag effects", The Review of Financial Studies, Vol. 33, No. 10, pp. 4721-4770.

Pastor, L. (2020), Data, Liquidity Factor Data, available at: https://faculty.chicagobooth.edu/lubos-pastor/data (accessed 28 September 2020).

Pastor, L., and Stambaugh, R. F. (2003), "Liquidity risk and expected stock returns", Journal of Political Economy, Vol. 111, No. 3, pp. 642-685.

Pastor, L., and Stambaugh, R. F. (2019), "Liquidity risk after 20 years", Critical Finance, Vol. 8, pp. 277-299.

Plyakha, Y., Uppal, R., and Vilkov, G. (2014), "Equal or value weighting? Implications for asset-pricing tests", working paper, EDHEC Business School.

Racicot, F. É., and Théoret, R. (2019), "Hedge fund return higher moments over the business cycle", Economic Modelling, Vol. 78, pp. 73-97.

Racicot, F. É., Rentz, W. F., and Théoret, R. (2018), "Testing the new Fama and French factors with illiquidity: a panel data investigation", Finance, Vol. 39, No. 3, pp. 45-102.

Rehman, Z., and Vilkov. G. (2012), "Risk-neutral skewness: return predictability and its sources", working paper, BlackRock and Frankfurt School of Finance and Management.

Sadka, R. (2006), "Momentum and post-earnings-announcement drift anomalies: the role of liquidity risk", Journal of Financial Economics, Vol. 80, No. 2, pp. 309-349.

Schopflocher, T. P., and Sullivan, P. J. (2005), "The relationship between skewness and kurtosis of a diffusing scalar", Boundary-Layer Meteorology, Vol. 115, No. 3, pp. 341-358.

Sharpe, W. F. (1964), "Capital asset prices: a theory of market equilibrium under conditions of risk", The Journal of Finance, Vol. 19, No. 3, pp. 425-442.

Stilger, P., Kostakis, A., and Poon, S. (2016), "What does risk-neutral skewness tell us about future stock returns?", Management Science, Vol. 63, No. 6, pp. 1814-1834.

Wen, Y. C., and Li, B. (2020), "Lagged country returns and international stock return predictability during business cycle recession periods", Applied Economics, Vol. 52, No. 46, pp. 5005-5019.

Wilkins, J. E. (1944), “A note on skewness and kurtosis”, The Annals of Mathematical Statistics, Vol. 15, No. 3, pp. 333-335.

Wu, J. (2015), "Industry momentum and mutual fund performance", working paper, Indiana University. 
Wu, Y., and Mazouz, K. (2016), "Long-term industry reversals”, Journal of Banking and Finance, Vol. 68, pp. 236-250.

Yu, J. (2002), "Forecasting volatility in the New Zealand stock market", Applied Financial Economics, Vol. 12, No. 3, pp. 193-202.

Zaremba, A. (2016), "Investor sentiment, limits on arbitrage, and the performance of cross-country stock market anomalies", Journal of Behavioral and Experimental Finance, Vol. 9, pp. 136-163.

Zhang, Y. (2005), "Individual skewness and the cross-section of average stock returns", working Paper, Yale University. 
Table I. Summary statistics by industry

\begin{tabular}{|c|c|c|c|c|c|c|c|}
\hline \multicolumn{2}{|c|}{ No. Industry } & \multirow{2}{*}{$\frac{\text { Mean }}{0.759}$} & \multirow{2}{*}{$\frac{\text { Volatility }}{1.571}$} & \multirow{2}{*}{$\begin{array}{l}\text { Skewness } \\
0.007\end{array}$} & \multirow{2}{*}{$\frac{\text { Kurtosis }}{5.150}$} & \multicolumn{2}{|c|}{ Jarque-Bera Excess R } \\
\hline 1 & Agriculture & & & & & 153.996 & 0.381 \\
\hline 2 & Food Products & 0.977 & 1.112 & 0.466 & 4.691 & 104.421 & 0.599 \\
\hline 3 & Candy and Soda & 0.90 & 1.605 & -0.004 & 6.529 & 398.399 & 0.523 \\
\hline 4 & Beer and Liquor & 0.987 & 1.30 & 0.146 & 5.183 & 195.078 & 0.61 \\
\hline 5 & Tobacco Products & 1.201 & 1.561 & 0.021 & 5.154 & 220.256 & 0.823 \\
\hline 6 & Recreation & 0.552 & 1.768 & -0.406 & 5.256 & 194.544 & 0.174 \\
\hline 7 & Entertainment & 1.012 & 1.970 & -0.373 & 6.286 & 415.831 & 0.634 \\
\hline 8 & Printing and Publishing & 0.678 & 1.452 & 0.031 & 4.994 & 130.172 & 0.30 \\
\hline 9 & Consumer Goods & 0.756 & 1.162 & -0.086 & 5.065 & 195.815 & 0.378 \\
\hline 10 & Apparel & 0.869 & 1.628 & -0.130 & 5.959 & 307.70 & 0.491 \\
\hline 11 & Healthcare & 0.625 & 2.014 & -0.571 & 7.598 & 664.317 & 0.248 \\
\hline 12 & Pharmaceutical Products & 0.878 & 1.310 & -0.131 & 4.268 & 119.124 & 0.501 \\
\hline 13 & Pharmaceutical Products & 0.929 & 1.244 & 0.362 & 4.855 & 116.195 & 0.551 \\
\hline 14 & Chemicals & 0.867 & 1.406 & -0.098 & 5.755 & 292.506 & 0.489 \\
\hline 15 & Rubber and Plastic Products & 0.839 & 1.485 & -0.326 & 6.278 & 424.231 & 0.461 \\
\hline 16 & Textiles & 0.683 & 1.817 & -0.314 & 9.440 & 1181.843 & 0.305 \\
\hline 17 & Construction Materials & 0.819 & 1.559 & -0.248 & 7.133 & 572.858 & 0.442 \\
\hline 18 & Construction & 0.674 & 1.789 & -0.236 & 4.659 & 115.201 & 0.296 \\
\hline 19 & Steel Works etc. & 0.436 & 1.910 & -0.504 & 5.877 & 277.455 & 0.058 \\
\hline 20 & Fabricated Products & 0.472 & 1.80 & -0.327 & 4.581 & 101.998 & 0.094 \\
\hline 21 & Machinery & 0.799 & 1.598 & -0.50 & 6.434 & 473.334 & 0.421 \\
\hline 22 & Electrical Equipment & 0.942 & 1.572 & -0.166 & 5.501 & 260.532 & 0.565 \\
\hline 23 & Automobiles and Trucks & 0.608 & 1.715 & -0.285 & 8.344 & 819.235 & 0.23 \\
\hline 24 & Aircraft & 1.023 & 1.661 & -0.292 & 5.545 & 303.479 & 0.645 \\
\hline 25 & Shipbuilding, Railroad Equipment & 0.814 & 1.824 & -0.128 & 4.974 & 145.15 & 0.437 \\
\hline 26 & Defense & 1.114 & 1.618 & -0.165 & 5.666 & 319.855 & 0.736 \\
\hline 27 & Precious Metals & 0.381 & 2.570 & 0.062 & 4.557 & 61.707 & 0.003 \\
\hline 28 & Non-Metallic and Industrial Metal Mining & 0.676 & 1.888 & -0.510 & 6.529 & 433.302 & 0.298 \\
\hline 29 & Coal & 0.299 & 2.668 & -0.316 & 4.965 & 117.132 & -0.078 \\
\hline 30 & Petroleum and Natural Gas & 0.840 & 1.393 & 0.209 & 3.892 & 34.408 & 0.462 \\
\hline 31 & Utilities & 0.834 & 1.007 & 0.278 & 3.805 & 44.503 & 0.456 \\
\hline 32 & Communication & 0.842 & 1.173 & 0.092 & 3.949 & 64.060 & 0.464 \\
\hline 33 & Personal Services & 0.399 & 1.658 & -0.496 & 5.343 & 204.309 & 0.022 \\
\hline 34 & Business Services & 0.893 & 1.615 & -0.111 & 4.627 & 125.449 & 0.515 \\
\hline 35 & Computers & 0.639 & 1.761 & -0.345 & 5.506 & 229.627 & 0.262 \\
\hline 36 & Electronic Equipment & 0.817 & 1.881 & -0.482 & 5.272 & 244.589 & 0.439 \\
\hline 37 & Measuring and Control Equipment & 0.803 & 1.756 & -0.222 & 4.687 & 130.562 & 0.425 \\
\hline 38 & Business Supplies & 0.807 & 1.369 & 0.155 & 5.353 & 179.261 & 0.429 \\
\hline 39 & Shipping Containers & 0.822 & 1.440 & -0.329 & 5.463 & 282.857 & 0.445 \\
\hline 40 & Transportation & 0.827 & 1.460 & -0.173 & 4.811 & 159.39 & 0.45 \\
\hline 41 & Wholesale & 0.805 & 1.365 & -0.353 & 6.488 & 486.952 & 0.427 \\
\hline 42 & Retail & 0.936 & 1.369 & -0.045 & 5.672 & 289.395 & 0.558 \\
\hline 43 & Restaurants, Hotels, Motels & 0.888 & 1.506 & -0.572 & 6.830 & 634.70 & 0.511 \\
\hline 44 & Banking & 0.807 & 1.515 & -0.314 & 5.551 & 279.639 & 0.43 \\
\hline 45 & Insurance & 0.917 & 1.367 & -0.154 & 5.377 & 262.416 & 0.539 \\
\hline 46 & Real Estate & 0.232 & 1.881 & -0.162 & 9.159 & 967.633 & -0.146 \\
\hline 47 & Trading & 0.906 & 1.564 & -0.322 & 4.671 & 177.253 & 0.528 \\
\hline 48 & Other & 0.287 & 1.654 & -0.792 & 5.899 & 319.957 & -0.091 \\
\hline
\end{tabular}

Notes: This table provides summary statistics of the monthly log returns for the 48 industries from January 1970 to December 2019 , comprising the mean return (\%), realized volatility, skewness, kurtosis, Jarque-Bera statistics using monthly industry returns, and excess returns (\%). 
Table II. Realized skewness and subsequent returns

\begin{tabular}{|c|c|c|c|c|c|c|c|c|}
\hline E & & Skewness & $\mathrm{H}$ & 3 & 6 & 9 & 12 & 24 \\
\hline \multirow[t]{8}{*}{1} & Low & -0.920 & 0.145 & 0.230 & 0.271 & 0.283 & 0.273 & 0.366 \\
\hline & 2 & -0.297 & 0.313 & 0.380 & 0.406 & 0.411 & 0.397 & 0.404 \\
\hline & 3 & 0.017 & 0.483 & 0.465 & 0.469 & 0.463 & 0.456 & 0.436 \\
\hline & 4 & 0.292 & 0.492 & 0.404 & 0.423 & 0.435 & 0.449 & 0.435 \\
\hline & 5 & 0.586 & 0.546 & 0.545 & 0.527 & 0.504 & 0.516 & 0.455 \\
\hline & High & 1.123 & 0.454 & 0.368 & 0.416 & 0.451 & 0.460 & 0.422 \\
\hline & $\mathrm{H}-\mathrm{L}$ & 2.044 & 0.308 & 0.137 & 0.144 & 0.167 & $0.186^{* *}$ & 0.056 \\
\hline & $t(H-L)$ & & $(1.03)$ & $(0.73)$ & (1.10) & (1.61) & $(2.15)$ & $(0.98)$ \\
\hline \multirow[t]{8}{*}{3} & Low & -0.792 & 0.214 & 0.203 & 0.268 & 0.272 & 0.265 & 0.366 \\
\hline & 2 & -0.256 & 0.344 & 0.445 & 0.443 & 0.414 & 0.389 & 0.404 \\
\hline & 3 & -0.020 & 0.446 & 0.510 & 0.506 & 0.486 & 0.473 & 0.448 \\
\hline & 4 & 0.183 & 0.467 & 0.511 & 0.491 & 0.463 & 0.453 & 0.429 \\
\hline & 5 & 0.414 & 0.514 & 0.465 & 0.483 & 0.484 & 0.497 & 0.451 \\
\hline & High & 0.880 & 0.440 & 0.410 & 0.415 & 0.479 & 0.486 & 0.422 \\
\hline & $\mathrm{H}-\mathrm{L}$ & 1.672 & 0.226 & 0.207 & 0.147 & $0.207 * *$ & $0.221 * *$ & 0.055 \\
\hline & $t(H-L)$ & & $(0.75)$ & (1.12) & (1.12) & $(2.01)$ & $(2.52)$ & $(0.97)$ \\
\hline \multirow[t]{8}{*}{6} & Low & -0.748 & 0.246 & 0.246 & 0.253 & 0.225 & 0.262 & 0.361 \\
\hline & 2 & -0.257 & 0.476 & 0.477 & 0.436 & 0.387 & 0.380 & 0.407 \\
\hline & 3 & -0.062 & 0.547 & 0.531 & 0.513 & 0.493 & 0.472 & 0.446 \\
\hline & 4 & 0.108 & 0.509 & 0.528 & 0.505 & 0.486 & 0.463 & 0.425 \\
\hline & 5 & 0.303 & 0.529 & 0.501 & 0.474 & 0.492 & 0.458 & 0.425 \\
\hline & High & 0.711 & 0.463 & 0.412 & 0.456 & 0.496 & 0.493 & 0.438 \\
\hline & $\mathrm{H}-\mathrm{L}$ & 1.459 & 0.216 & 0.166 & 0.202 & $0.271 * * *$ & $0.231 * * *$ & 0.077 \\
\hline & $t(H-L)$ & & $(0.73)$ & $(0.91)$ & $(1.56)$ & $(2.59)$ & $(2.62)$ & (1.34) \\
\hline \multirow[t]{8}{*}{9} & Low & -0.737 & 0.224 & 0.202 & 0.176 & 0.206 & 0.259 & 0.359 \\
\hline & 2 & -0.269 & 0.373 & 0.383 & 0.377 & 0.359 & 0.373 & 0.405 \\
\hline & 3 & -0.086 & 0.528 & 0.525 & 0.466 & 0.453 & 0.450 & 0.422 \\
\hline & 4 & 0.067 & 0.483 & 0.502 & 0.499 & 0.466 & 0.451 & 0.435 \\
\hline & 5 & 0.241 & 0.494 & 0.512 & 0.536 & 0.516 & 0.469 & 0.419 \\
\hline & High & 0.619 & 0.50 & 0.481 & 0.480 & 0.479 & 0.465 & 0.429 \\
\hline & $\mathrm{H}-\mathrm{L}$ & 1.356 & 0.275 & 0.278 & $0.303^{* *}$ & $0.273 * * *$ & $0.205^{* *}$ & 0.069 \\
\hline & $t(H-L)$ & & $(0.93)$ & $(1.52)$ & $(2.32)$ & $(2.60)$ & $(2.33)$ & (1.19) \\
\hline \multirow[t]{8}{*}{12} & Low & -0.734 & 0.135 & 0.125 & 0.199 & 0.242 & 0.280 & 0.367 \\
\hline & 2 & -0.282 & 0.386 & 0.343 & 0.320 & 0.330 & 0.358 & 0.405 \\
\hline & 3 & -0.108 & 0.458 & 0.439 & 0.423 & 0.433 & 0.455 & 0.424 \\
\hline & 4 & 0.035 & 0.488 & 0.557 & 0.513 & 0.489 & 0.465 & 0.421 \\
\hline & 5 & 0.199 & 0.541 & 0.516 & 0.517 & 0.471 & 0.435 & 0.418 \\
\hline & High & 0.560 & 0.561 & 0.509 & 0.455 & 0.466 & 0.453 & 0.417 \\
\hline & $\mathrm{H}-\mathrm{L}$ & 1.294 & 0.425 & $0.383 * *$ & $0.255^{* *}$ & $0.223 * *$ & $0.172 * *$ & 0.050 \\
\hline & $t(H-L)$ & & $(1.44)$ & $(2.12)$ & $(1.98)$ & $(2.15)$ & $(1.96)$ & $(0.88)$ \\
\hline \multirow[t]{8}{*}{24} & Low & -0.774 & 0.251 & 0.260 & 0.311 & 0.327 & 0.353 & 0.460 \\
\hline & 2 & -0.351 & 0.407 & 0.409 & 0.411 & 0.423 & 0.437 & 0.425 \\
\hline & 3 & -0.191 & 0.405 & 0.413 & 0.415 & 0.432 & 0.426 & 0.421 \\
\hline & 4 & -0.061 & 0.511 & 0.463 & 0.386 & 0.360 & 0.356 & 0.435 \\
\hline & 5 & 0.088 & 0.465 & 0.421 & 0.427 & 0.412 & 0.406 & 0.422 \\
\hline & High & 0.419 & 0.447 & 0.457 & 0.440 & 0.446 & 0.433 & 0.394 \\
\hline & $\mathrm{H}-\mathrm{L}$ & 1.193 & 0.196 & 0.196 & 0.129 & 0.119 & 0.079 & -0.065 \\
\hline & $t(H-L)$ & & $(0.65)$ & $(1.08)$ & $(0.99)$ & $(1.14)$ & $(0.89)$ & $(-1.11)$ \\
\hline
\end{tabular}

Note: This table provides the equal-weighted excess returns (\%) for each ranked group using realized skewness calculated on value-weighted industry daily returns over the selected estimation $(E)$ and holding $(H)$ periods from January 1970 to December 2019. "Skewness" reports average realized skewness for each ranked portfolio. "Low" ("High") represent the group with the lowest (highest) skewness. " $H-L$ " reports equal-weighted returns earned on the spread of skewness. $t$-statistics are in parentheses. $* * *$, and $* * *$ denote significance at the $10 \%, 5 \%$, and $1 \%$ levels, respectively. 
Table III. Adjusted returns and realized skewness

\begin{tabular}{|c|c|c|c|c|c|c|c|c|c|c|c|c|c|}
\hline E & $\alpha \mathrm{H}$ & 1 & & 3 & & 6 & & 9 & & 12 & & 24 & 4 \\
\hline \multirow[t]{4}{*}{1} & $\alpha_{C}$ & $0.0034 * * *$ & $(2.84)$ & $0.0018^{* *}$ & $(2.50)$ & $0.0016^{* * *}$ & $(3.20)$ & $0.0018 * * *$ & $(3.43)$ & $0.0020 * * *$ & * (4.13) & 0.0005 & $(1.32)$ \\
\hline & $\alpha_{3}$ & $0.0034 * * *$ & $(2.85)$ & $0.0022 * * *$ & (2.99) & $0.0019^{* * *}$ & $(3.66)$ & $0.0021^{* * *}$ & $(3.94)$ & $0.0023^{* * *}$ & * (4.03) & $0.0007 * *$ & (1.99) \\
\hline & $\alpha_{5}$ & $0.0035 * * *$ & (2.68) & $0.0016^{* *}$ & $(2.16)$ & $0.0018 * * *$ & $(3.03)$ & $0.0024 * * *$ & $(3.42)$ & $0.0022 * * *$ & * $(2.88)$ & 0.0007 & (1.40) \\
\hline & $\alpha_{6}$ & $0.0036 * * *$ & $(2.74)$ & $0.0018 * *$ & $(2.30)$ & $0.0018 * * *$ & $(2.87)$ & $0.0024 * * *$ & $(3.40)$ & $0.0022 * * *$ & * $(2.83)$ & $0.0009 *$ & (1.74) \\
\hline \multirow[t]{4}{*}{3} & $\alpha_{C}$ & $0.0032 * *$ & $(2.27)$ & $0.0028 * * *$ & $(2.84)$ & $0.0019 * * *$ & $(2.85)$ & $0.0023 * * *$ & $(3.60)$ & $0.0026^{* * *}$ & * $(4.08)$ & 0.0007 & $(1.20)$ \\
\hline & $\alpha_{3}$ & $0.0034 * *$ & $(2.33)$ & $0.0031 * * *$ & $(3.16)$ & $0.0020 * * *$ & $(2.80)$ & $0.0023 * * *$ & $(3.54)$ & $0.0026 * * *$ & * $(3.87)$ & 0.0008 & $(1.25)$ \\
\hline & $\alpha_{5}$ & $0.0030 * *$ & (1.99) & $0.0025 * *$ & $(2.31)$ & $0.0019 * *$ & $(2.26)$ & $0.0026 * * *$ & $(2.98)$ & $0.0025 * * *$ & * $(2.80)$ & 0.0004 & $(0.63)$ \\
\hline & $\alpha_{6}$ & $0.0033^{* *}$ & $(2.16)$ & $0.0026^{* *}$ & (2.44) & $0.0018^{* *}$ & $(2.12)$ & $0.0025^{* * *}$ & $(2.86)$ & $0.0024 * * *$ & * $(2.79)$ & 0.0006 & $(0.93)$ \\
\hline \multirow[t]{4}{*}{6} & $\alpha_{C}$ & $0.0032 * *$ & $(2.55)$ & $0.0026^{* *}$ & $(2.48)$ & $0.0028 * * *$ & $(3.08)$ & $0.0032 * * *$ & $(3.55)$ & $0.0031 * * *$ & * $(3.79)$ & 0.0011 & $(1.41)$ \\
\hline & $\alpha_{3}$ & $0.0035^{* * *}$ & $(2.86)$ & $0.0028 * * *$ & $(2.69)$ & $0.0028 * * *$ & $(3.24)$ & $0.0034 * * *$ & $(3.73)$ & $0.0033 * * *$ & * $(4.20)$ & 0.0013 & $(1.51)$ \\
\hline & $\alpha_{5}$ & $0.0032 * *$ & (2.49) & $0.0023^{* *}$ & (2.04) & $0.0030 * * *$ & $(2.96)$ & $0.0039 * * *$ & $(3.56)$ & $0.0036^{* * *}$ & * $(3.91)$ & 0.0014 & $(1.56)$ \\
\hline & $\alpha_{6}$ & $0.0034 * * *$ & $(2.68)$ & $0.0024 * *$ & $(2.15)$ & $0.0029 * * *$ & $(2.78)$ & $0.0037 * * *$ & $(3.36)$ & $0.0035 * * *$ & * $(3.85)$ & $0.0016^{*}$ & (1.79) \\
\hline \multirow[t]{4}{*}{9} & $\alpha_{C}$ & $0.0035 * * *$ & $(2.65)$ & $0.0037 * * *$ & $(3.31)$ & $0.0038 * * *$ & $(3.73)$ & $0.0033 * * *$ & $(3.22)$ & $0.0028 * * *$ & * $(3.02)$ & 0.0011 & (1.41) \\
\hline & $\alpha_{3}$ & $0.0039 * * *$ & $(3.04)$ & $0.0039 * * *$ & $(3.54)$ & $0.0039 * * *$ & $(3.73)$ & $0.0035^{* * *}$ & $(3.37)$ & $0.0031 * * *$ & * $(3.55)$ & 0.0014 & (1.64) \\
\hline & $\alpha_{5}$ & $0.0040 * * *$ & $(3.10)$ & $0.0039 * * *$ & (3.18) & $0.0043 * * *$ & $(3.51)$ & $0.0044 * * *$ & $(3.77)$ & $0.0037 * * *$ & * (3.98) & $0.0020 * *$ & $(2.34)$ \\
\hline & $\alpha_{6}$ & $0.0041^{* * *}$ & (3.08) & $0.0039 * * *$ & (3.14) & $0.0041 * * *$ & $(3.35)$ & $0.0041 * * *$ & $(3.57)$ & $0.0036^{* * *}$ & * $(3.83)$ & $0.0023^{* *}$ & $(2.52)$ \\
\hline \multirow[t]{4}{*}{12} & $\alpha_{C}$ & $0.0050 * * *$ & (3.83) & $0.0048 * * *$ & $(4.10)$ & $0.0033^{* * *}$ & $(3.04)$ & $0.0029 * * *$ & $(2.58)$ & $0.0024 * *$ & $(2.39)$ & 0.0010 & (1.19) \\
\hline & $\alpha_{3}$ & $0.0053 * * *$ & $(4.16)$ & $0.0050 * * *$ & $(4.41)$ & $0.0033 * * *$ & $(3.20)$ & $0.0031 * * *$ & $(2.98)$ & $0.0029 * * *$ & * $(3.11)$ & 0.0013 & (1.53) \\
\hline & $\alpha_{5}$ & $0.0055^{* * *}$ & (4.19) & $0.0053^{* * *}$ & $(4.36)$ & $0.0043^{* * *}$ & $(3.81)$ & $0.0044 * * *$ & $(4.07)$ & $0.0040 * * *$ & * $(4.30)$ & $0.0020 * *$ & $(2.31)$ \\
\hline & $\alpha_{6}$ & $0.0055^{* * *}$ & (4.13) & $0.0054 * * *$ & (4.33) & $0.0040 * * *$ & $(3.58)$ & $0.0042 * * *$ & $(3.86)$ & $0.0039 * * *$ & * $(4.17)$ & $0.0023^{* *}$ & $(2.53)$ \\
\hline \multirow[t]{4}{*}{24} & $\alpha_{C}$ & $0.0028 * *$ & (2.06) & $0.0031 * * *$ & $(2.67)$ & $0.0023 * *$ & $(2.08)$ & $0.0021 * *$ & (1.98) & $0.0016^{*}$ & (1.74) & -0.0001 & $(-0.21)$ \\
\hline & $\alpha_{3}$ & $0.0033^{* * *}$ & (2.67) & $0.0036^{* * *}$ & $(3.38)$ & $0.0027 * *$ & $(2.47)$ & $0.0027 * * *$ & $(2.66)$ & $0.0024 * * *$ & * $(2.81)$ & 0.0005 & $(0.82)$ \\
\hline & $\alpha_{5}$ & $0.0036^{* * *}$ & $(2.92)$ & $0.0039 * * *$ & (3.56) & $0.0036^{* * *}$ & $(3.39)$ & $0.0038 * * *$ & $(3.88)$ & $0.0034 * * *$ & * $(3.90)$ & 0.0005 & $(0.66)$ \\
\hline & $\alpha_{6}$ & $0.0038 * * *$ & $(3.01)$ & $0.0039 * * *$ & $(3.49)$ & $0.0034 * * *$ & $(3.06)$ & $0.0037 * * *$ & $(3.54)$ & $0.0035 * * *$ & * (3.68) & 0.0010 & $(1.33)$ \\
\hline
\end{tabular}

Note: This table provides the abnormal returns of each zero-cost portfolio using realized skewness calculated on value-weighted industry returns after controlling for common risk factors over different estimation $(E)$ and holding $(H)$ periods from January 1970 to December 2019. $\boldsymbol{\alpha}_{\boldsymbol{C}}, \boldsymbol{\alpha}_{3}, \boldsymbol{\alpha}_{5}$, and $\boldsymbol{\alpha}_{\mathbf{6}}$ are abnormal returns adjusted by the CAPM, Fama-French three- and fivefactor models, and the six-factor model adding illiquidity factor, respectively. Newey-West adjusted $t$-statistics are in parentheses. $* * *$, and $* * *$ denote significance at the $10 \%, 5 \%$, and $1 \%$ levels, respectively. 
Table IV. Realized kurtosis and subsequent returns

\begin{tabular}{|c|c|c|c|c|c|c|c|c|c|}
\hline $\mathrm{E}$ & & Kurtosis & Skewness & $\mathrm{H}$ & 3 & 6 & 9 & 12 & 24 \\
\hline \multirow[t]{8}{*}{1} & Low & 2.101 & 0.116 & 0.415 & 0.415 & 0.419 & 0.415 & 0.436 & 0.406 \\
\hline & 2 & 2.474 & 0.122 & 0.462 & 0.460 & 0.437 & 0.422 & 0.421 & 0.408 \\
\hline & 3 & 2.771 & 0.134 & 0.368 & 0.355 & 0.416 & 0.424 & 0.414 & 0.412 \\
\hline & 4 & 3.112 & 0.129 & 0.376 & 0.409 & 0.405 & 0.433 & 0.430 & 0.437 \\
\hline & 5 & 3.598 & 0.144 & 0.470 & 0.442 & 0.477 & 0.479 & 0.466 & 0.450 \\
\hline & High & 5.097 & 0.156 & 0.342 & 0.312 & 0.359 & 0.375 & 0.385 & 0.406 \\
\hline & $\mathrm{H}-\mathrm{L}$ & 2.995 & 0.040 & -0.073 & -0.102 & -0.060 & -0.040 & -0.051 & 0.001 \\
\hline & $t(H-L)$ & & & $(-0.25)$ & $(-0.56)$ & $(-0.47)$ & $(-0.39)$ & $(-0.59)$ & $(0.01)$ \\
\hline \multirow[t]{8}{*}{3} & Low & 2.705 & 0.118 & 0.447 & 0.434 & 0.407 & 0.413 & 0.415 & 0.382 \\
\hline & 2 & 3.124 & 0.102 & 0.392 & 0.438 & 0.459 & 0.434 & 0.444 & 0.418 \\
\hline & 3 & 3.457 & 0.084 & 0.436 & 0.512 & 0.522 & 0.486 & 0.459 & 0.435 \\
\hline & 4 & 3.830 & 0.075 & 0.450 & 0.502 & 0.484 & 0.472 & 0.466 & 0.445 \\
\hline & 5 & 4.373 & 0.065 & 0.422 & 0.369 & 0.414 & 0.440 & 0.424 & 0.436 \\
\hline & High & 6.592 & -0.003 & 0.276 & 0.289 & 0.320 & 0.353 & 0.357 & 0.404 \\
\hline & $\mathrm{H}-\mathrm{L}$ & 3.887 & -0.121 & -0.170 & -0.145 & -0.087 & -0.060 & -0.058 & 0.022 \\
\hline & $t(H-L)$ & & & $(-0.57)$ & $(-0.80)$ & $(-0.67)$ & $(-0.58)$ & $(-0.65)$ & $(0.38)$ \\
\hline \multirow[t]{8}{*}{6} & Low & 3.158 & 0.092 & 0.554 & 0.471 & 0.439 & 0.446 & 0.417 & 0.356 \\
\hline & 2 & 3.619 & 0.065 & 0.542 & 0.537 & 0.484 & 0.456 & 0.452 & 0.449 \\
\hline & 3 & 3.995 & 0.036 & 0.519 & 0.529 & 0.501 & 0.483 & 0.447 & 0.431 \\
\hline & 4 & 4.411 & 0.016 & 0.510 & 0.497 & 0.476 & 0.437 & 0.423 & 0.431 \\
\hline & 5 & 5.032 & -0.006 & 0.358 & 0.390 & 0.420 & 0.422 & 0.421 & 0.440 \\
\hline & High & 7.839 & -0.112 & 0.287 & 0.273 & 0.318 & 0.336 & 0.366 & 0.392 \\
\hline & $\mathrm{H}-\mathrm{L}$ & 4.681 & -0.204 & -0.266 & -0.196 & -0.120 & -0.110 & -0.051 & 0.036 \\
\hline & $t(H-L)$ & & & $(-0.90)$ & $(-1.09)$ & $(-0.93)$ & $(-1.06)$ & $(-0.57)$ & $(0.62)$ \\
\hline \multirow[t]{8}{*}{9} & Low & 3.470 & 0.072 & 0.447 & 0.427 & 0.412 & 0.401 & 0.364 & 0.339 \\
\hline & 2 & 3.985 & 0.036 & 0.563 & 0.456 & 0.462 & 0.439 & 0.445 & 0.423 \\
\hline & 3 & 4.411 & 0.005 & 0.442 & 0.496 & 0.447 & 0.441 & 0.438 & 0.436 \\
\hline & 4 & 4.881 & -0.024 & 0.468 & 0.485 & 0.473 & 0.447 & 0.431 & 0.449 \\
\hline & 5 & 5.595 & -0.043 & 0.429 & 0.423 & 0.401 & 0.396 & 0.414 & 0.439 \\
\hline & High & 8.778 & -0.175 & 0.254 & 0.318 & 0.338 & 0.356 & 0.375 & 0.382 \\
\hline & $\mathrm{H}-\mathrm{L}$ & 5.308 & -0.246 & -0.192 & -0.109 & -0.074 & -0.045 & 0.011 & 0.043 \\
\hline & $t(H-L)$ & & & $(-0.65)$ & $(-0.62)$ & $(-0.57)$ & $(-0.43)$ & $(0.12)$ & $(0.74)$ \\
\hline \multirow[t]{8}{*}{12} & Low & 3.725 & 0.057 & 0.447 & 0.428 & 0.411 & 0.371 & 0.336 & 0.319 \\
\hline & 2 & 4.309 & 0.005 & 0.475 & 0.458 & 0.445 & 0.447 & 0.434 & 0.427 \\
\hline & 3 & 4.790 & -0.012 & 0.511 & 0.534 & 0.476 & 0.470 & 0.473 & 0.459 \\
\hline & 4 & 5.332 & -0.049 & 0.427 & 0.429 & 0.439 & 0.442 & 0.463 & 0.442 \\
\hline & 5 & 6.115 & -0.072 & 0.415 & 0.300 & 0.323 & 0.360 & 0.373 & 0.427 \\
\hline & High & 9.509 & -0.222 & 0.293 & 0.339 & 0.334 & 0.341 & 0.366 & 0.378 \\
\hline & $\mathrm{H}-\mathrm{L}$ & 5.783 & -0.279 & -0.153 & -0.089 & -0.077 & -0.030 & 0.030 & 0.059 \\
\hline & $t(H-L)$ & & & $(-0.52)$ & $(-0.49)$ & $(-0.59)$ & $(-0.29)$ & $(0.34)$ & $(1.01)$ \\
\hline \multirow[t]{8}{*}{24} & Low & 4.521 & 0.004 & 0.406 & 0.348 & 0.330 & 0.337 & 0.337 & 0.378 \\
\hline & 2 & 5.430 & -0.070 & 0.410 & 0.391 & 0.414 & 0.401 & 0.396 & 0.397 \\
\hline & 3 & 6.249 & -0.099 & 0.548 & 0.473 & 0.468 & 0.486 & 0.474 & 0.460 \\
\hline & 4 & 7.012 & -0.135 & 0.475 & 0.557 & 0.536 & 0.502 & 0.517 & 0.495 \\
\hline & 5 & 8.120 & -0.182 & 0.281 & 0.293 & 0.315 & 0.352 & 0.343 & 0.388 \\
\hline & High & 12.120 & -0.352 & 0.366 & 0.360 & 0.327 & 0.322 & 0.344 & 0.438 \\
\hline & $\mathrm{H}-\mathrm{L}$ & 7.598 & -0.356 & -0.040 & 0.012 & -0.003 & -0.015 & 0.007 & 0.060 \\
\hline & $t(H-L)$ & & & $(-0.13)$ & $(0.07)$ & $(-0.03)$ & $(-0.14)$ & $(0.08)$ & $(1.0)$ \\
\hline
\end{tabular}

Note: This table provides equal-weighted excess returns (\%) for each ranked group using realized kurtosis calculated on valueweighted industry returns over the selected estimation $(E)$ and holding periods $(H)$ from January 1970 to December 2019. "Kurtosis (Skewness)" reports average realized kurtosis (skewness) for each ranked portfolio. $t$-statistics are in parentheses. $*, * *$, and $* * *$ denote significance at the $10 \%, 5 \%$, and $1 \%$ levels, respectively. 
Table V. Realized skewness and returns over business cycles

\begin{tabular}{|c|c|c|c|c|c|c|c|c|c|c|c|c|c|c|c|}
\hline & & & $\mathrm{H}$ & 3 & 6 & 9 & 12 & 24 & & 1 & 3 & 6 & 9 & 12 & 24 \\
\hline & & & \multicolumn{6}{|c|}{ Returns in Expansions } & \multicolumn{7}{|c|}{ Returns in Recessions } \\
\hline $\mathrm{E}$ & & Skewnes & & & & & & & Skewness & & & & & & \\
\hline \multirow[t]{4}{*}{1} & Low & -0.932 & 0.371 & 0.413 & 0.284 & 0.240 & 0.201 & 0.209 & -0.906 & -0.130 & 0.007 & 0.256 & 0.338 & 0.365 & 0.568 \\
\hline & High & 1.130 & 0.621 & 0.525 & 0.425 & 0.436 & 0.398 & 0.257 & 1.115 & 0.250 & 0.175 & 0.405 & 0.470 & 0.540 & 0.634 \\
\hline & $\mathrm{H}-\mathrm{L}$ & 2.061 & 0.249 & 0.112 & 0.141 & $0.196^{*}$ & $0.196 * *$ & 0.049 & 2.021 & 0.381 & 0.168 & 0.148 & 0.132 & 0.175 & 0.066 \\
\hline & $t(H-L)$ & & $(0.69)$ & $(0.52)$ & $(1.03)$ & $(1.88)$ & $(2.21)$ & $(0.62)$ & & $(0.76)$ & $(0.52)$ & $(0.62)$ & $(0.68)$ & $(1.08)$ & $(0.83)$ \\
\hline \multirow[t]{4}{*}{3} & Low & -0.790 & 0.379 & 0.343 & 0.266 & 0.206 & 0.189 & 0.213 & -0.775 & 0.011 & 0.029 & 0.271 & 0.355 & 0.364 & 0.564 \\
\hline & High & 0.879 & 0.644 & 0.512 & 0.413 & 0.438 & 0.423 & 0.258 & 0.889 & 0.189 & 0.284 & 0.418 & 0.532 & 0.568 & 0.632 \\
\hline & $\mathrm{H}-\mathrm{L}$ & 1.669 & 0.264 & 0.168 & 0.146 & $0.231 * *$ & $0.234 * * *$ & 0.045 & 1.664 & 0.178 & 0.255 & 0.147 & 0.177 & 0.204 & 0.068 \\
\hline & $t(H-L)$ & & $(0.73)$ & $(0.79)$ & $(1.07)$ & $(2.26)$ & $(2.66)$ & $(0.57)$ & & $(0.35)$ & $(0.80)$ & $(0.61)$ & $(0.91)$ & $(1.23)$ & $(0.88)$ \\
\hline \multirow[t]{4}{*}{6} & Low & -0.739 & 0.306 & 0.322 & 0.186 & 0.137 & 0.160 & 0.196 & -0.737 & 0.171 & 0.151 & 0.338 & 0.338 & 0.394 & 0.576 \\
\hline & High & 0.728 & 0.570 & 0.496 & 0.459 & 0.485 & 0.442 & 0.265 & 0.703 & 0.330 & 0.307 & 0.453 & 0.511 & 0.560 & 0.664 \\
\hline & $\mathrm{H}-\mathrm{L}$ & 1.467 & 0.263 & 0.174 & $0.272 * *$ & $0.347 * * *$ & $0.281 * * *$ & 0.069 & 1.440 & 0.159 & 0.155 & 0.114 & 0.173 & 0.166 & 0.088 \\
\hline & $t(H-L)$ & & $(0.73)$ & $(0.82)$ & $(2.02)$ & $(3.34)$ & $(3.17)$ & $(0.86)$ & & $(0.32)$ & $(0.49)$ & $(0.48)$ & $(0.87)$ & $(1.0)$ & (1.13) \\
\hline \multirow[t]{4}{*}{9} & Low & -0.739 & 0.295 & 0.258 & 0.132 & 0.130 & 0.155 & 0.185 & -0.718 & 0.136 & 0.131 & 0.232 & 0.304 & 0.397 & 0.589 \\
\hline & High & 0.645 & 0.645 & 0.587 & 0.503 & 0.475 & 0.413 & 0.265 & 0.597 & 0.319 & 0.348 & 0.450 & 0.485 & 0.534 & 0.645 \\
\hline & $\mathrm{H}-\mathrm{L}$ & 1.385 & 0.349 & 0.327 & $0.371 * * *$ & $0.344 * * *$ & $0.258 * * *$ & 0.080 & 1.315 & 0.182 & 0.217 & 0.217 & 0.180 & 0.137 & 0.056 \\
\hline & $t(H-L)$ & & $(0.96)$ & $(1.53)$ & $(2.69)$ & $(3.23)$ & $(2.82)$ & $(0.99)$ & & $(0.37)$ & $(0.69)$ & $(0.90)$ & $(0.91)$ & $(0.83)$ & $(0.71)$ \\
\hline \multirow[t]{4}{*}{12} & 2 Low & -0.751 & 0.211 & 0.233 & 0.185 & 0.178 & 0.183 & 0.178 & -0.687 & 0.039 & -0.012 & 0.218 & 0.325 & 0.408 & 0.617 \\
\hline & High & 0.587 & 0.713 & 0.662 & 0.490 & 0.461 & 0.403 & 0.253 & 0.542 & 0.369 & 0.315 & 0.411 & 0.472 & 0.519 & 0.635 \\
\hline & $\mathrm{H}-\mathrm{L}$ & 1.338 & 0.501 & $0.427 * *$ & $0.304 * *$ & $0.282 * * *$ & $0.219 * *$ & 0.075 & 1.229 & 0.330 & 0.327 & 0.193 & 0.146 & 0.110 & 0.017 \\
\hline & $t(H-L)$ & & $(1.39)$ & $(2.02)$ & $(2.26)$ & $(2.71)$ & $(2.45)$ & $(0.95)$ & & $(0.67)$ & $(1.05)$ & $(0.81)$ & $(0.74)$ & $(0.67)$ & $(0.22)$ \\
\hline \multirow[t]{4}{*}{24} & 4 Low & -0.814 & 0.295 & 0.298 & 0.201 & 0.179 & 0.177 & 0.230 & -0.932 & 0.197 & 0.213 & 0.447 & 0.513 & 0.578 & 0.754 \\
\hline & High & 0.425 & 0.589 & 0.560 & 0.430 & 0.390 & 0.342 & 0.238 & 1.130 & 0.275 & 0.330 & 0.453 & 0.517 & 0.548 & 0.595 \\
\hline & $\mathrm{H}-\mathrm{L}$ & 1.239 & 0.293 & 0.261 & $0.229 *$ & $0.211 * *$ & $0.165^{*}$ & 0.008 & 2.061 & 0.078 & 0.117 & 0.006 & 0.004 & -0.029 & -0.159 \\
\hline & $t(H-L)$ & & $(0.80)$ & $(1.22)$ & $(1.66)$ & $(1.96)$ & $(1.80)$ & $(0.10)$ & & $(0.16)$ & $(0.38)$ & $(0.02)$ & $(0.02)$ & $(-0.18)$ & $(-2.06)$ \\
\hline
\end{tabular}


Table VI. Adjusted returns and realized skewness in business cycle expansions

\begin{tabular}{|c|c|c|c|c|c|c|c|c|c|c|c|c|}
\hline $\mathrm{E}$ & $\boldsymbol{\alpha} \mathrm{H}$ & 1 & & 3 & & 6 & & 9 & 12 & & 24 & \\
\hline \multirow[t]{4}{*}{1} & $\alpha_{C}$ & $0.0037 * *$ & $(2.26)$ & $0.0023 * *$ & $(2.40)$ & $0.0017 * *$ & $(2.43)$ & $0.0030 * * *(3.58)$ & $0.0027 * * *$ & $(3.47)$ & 0.0006 & (1.11) \\
\hline & $\alpha_{3}$ & $0.0040 * *$ & $(2.40)$ & $0.0027 * * *$ & $(3.14)$ & $0.0020 * * *$ & $(2.72)$ & $0.0031^{* * *}(3.61)$ & $0.0030 * * *$ & $(3.36)$ & 0.0008 & $(1.49)$ \\
\hline & $\alpha_{5}$ & $0.0045 * * *$ & $(2.62)$ & $0.0029 * * *$ & $(3.25)$ & $0.0022 * * *$ & $(3.05)$ & $0.0036^{* * *}(3.79)$ & $0.0033 * * *$ & $(3.40)$ & 0.0008 & (1.48) \\
\hline & $\alpha_{6}$ & $0.0045 * * *$ & $(2.58)$ & $0.0029 * * *$ & $(3.25)$ & $0.0027 * * *$ & $(3.63)$ & $0.0039 * * *(3.82)$ & $0.0037 * * *$ & $(3.31)$ & $0.0011^{*}$ & $(1.77)$ \\
\hline & $\alpha_{C}$ & $0.0043 * * *$ & $(2.89)$ & $0.0025 * *$ & $(2.20)$ & $0.0021 * *$ & $(2.19)$ & $0.0033 * * *(2.90)$ & $0.0031 * * *$ & $(3.01)$ & 0.0006 & $(0.66)$ \\
\hline & $\alpha_{3}$ & $0.0047 * * *$ & $(3.05)$ & $0.0029 * *$ & $(2.57)$ & $0.0022 * *$ & $(2.19)$ & $0.0031 * * *(2.82)$ & $0.0033 * * *$ & (3.07) & 0.0008 & $(0.90)$ \\
\hline & $\alpha_{5}$ & $0.0055 * * *$ & $(3.68)$ & $0.0035^{* * *}$ & $(3.33)$ & $0.0028 * * *$ & $(2.97)$ & $0.0038 * * *(3.55)$ & $0.0039 * * *$ & $(3.76)$ & $0.0012 *$ & $(1.67)$ \\
\hline & $\alpha_{6}$ & $0.0058 * * *$ & $(3.93)$ & $0.0036 * * *$ & $(3.44)$ & $0.0029 * * *$ & $(3.03)$ & $0.0037 * * *(3.10)$ & $0.0041 * * *$ & $(3.55)$ & $0.0014 *$ & $(1.79)$ \\
\hline \multirow[t]{4}{*}{6} & $\alpha_{C}$ & $0.0040 * * *$ & $(2.67)$ & $0.0028^{*}$ & $(1.82)$ & $0.0037 * * *$ & $(2.71)$ & $0.0042 * * *(2.79)$ & $0.0033 * *$ & $(2.44)$ & 0.0007 & $(0.61)$ \\
\hline & $\alpha_{3}$ & $0.0042 * * *$ & $(2.74)$ & $0.0026^{*}$ & $(1.86)$ & $0.0035 * * *$ & $(2.64)$ & $0.0044 * * *(3.16)$ & $0.0038 * * *$ & $(3.02)$ & 0.0011 & $(0.91)$ \\
\hline & $\alpha_{5}$ & $0.0047 * * *$ & $(3.05)$ & $0.0029 * *$ & $(2.05)$ & $0.0040 * * *$ & $(2.92)$ & $0.0055^{* * *}(4.15)$ & $0.0047 * * *$ & $(4.09)$ & $0.0022 * *$ & $(2.33)$ \\
\hline & $\alpha_{6}$ & $0.0048 * * *$ & $(3.10)$ & $0.0026^{*}$ & $(1.78)$ & $0.0038 * * *$ & $(2.63)$ & $0.0056^{* * *}(3.99)$ & $0.0053 * * *$ & $(4.41)$ & $0.0026^{* *}$ & $(2.50)$ \\
\hline & $\alpha_{C}$ & $0.0048 * * *$ & $(2.89)$ & $0.0044 * * *$ & $(2.68)$ & $0.0044 * * *$ & $(2.95)$ & $0.0038 * * \quad(2.32)$ & $0.0027 *$ & $(1.73)$ & 0.0009 & $(0.74)$ \\
\hline & $\alpha_{3}$ & $0.0051 * * *$ & $(3.10)$ & $0.0044 * * *$ & $(2.78)$ & $0.0046^{* * *}$ & $(3.08)$ & $0.0042 * * *(2.81)$ & $0.0034 * *$ & $(2.42)$ & 0.0014 & $(1.14)$ \\
\hline & $\alpha_{5}$ & $0.0056^{* * *}$ & $(3.39)$ & $0.0049 * * *$ & $(3.01)$ & $0.0053 * * *$ & $(3.50)$ & $0.0054 * * *(3.80)$ & $0.0045 * * *$ & $(3.57)$ & $0.0028 * * *$ & $(2.99)$ \\
\hline & $\alpha_{6}$ & $0.0055 * * *$ & $(3.29)$ & $0.0047 * * *$ & $(2.78)$ & $0.0056 * * *$ & $(3.59)$ & $0.0059 * * *(3.99)$ & $0.0053 * * *$ & $(4.10)$ & $0.0033 * * *$ & $(3.16)$ \\
\hline \multirow[t]{4}{*}{12} & $\alpha_{C}$ & $0.0061 * * *$ & $(3.31)$ & $0.0053 * * *$ & $(3.05)$ & $0.0036^{* *}$ & $(2.46)$ & $0.0033^{*} \quad(1.81)$ & 0.0024 & $(1.35)$ & 0.0009 & $(0.75)$ \\
\hline & $\alpha_{3}$ & $0.0063 * * *$ & $(3.49)$ & $0.0053 * * *$ & $(3.17)$ & $0.0036 * * *$ & $(2.62)$ & $0.0036^{* *} \quad(2.32)$ & $0.0031 * *$ & $(2.07)$ & 0.0014 & (1.17) \\
\hline & $\alpha_{5}$ & $0.0069 * * *$ & $(3.78)$ & $0.0060 * * *$ & $(3.51)$ & $0.0045 * * *$ & $(3.30)$ & $0.0050 * * *(3.56)$ & $0.0046 * * *$ & $(3.58)$ & $0.0028 * * *$ & $(2.81)$ \\
\hline & $\alpha_{6}$ & $0.0068 * * *$ & $(3.62)$ & $0.0059 * * *$ & $(3.31)$ & $0.0047 * * *$ & $(3.41)$ & $0.0057 * * *$ & $0.0058 * * *$ & $(4.64)$ & $0.0033 * * *$ & $(3.03)$ \\
\hline \multirow[t]{4}{*}{24} & $\alpha_{C}$ & $0.0042 * *$ & $(2.37)$ & $0.0042 * *$ & $(2.58)$ & $0.0034 * *$ & $(2.42)$ & $0.0029 *$ & 0.0021 & $(1.33)$ & 0.0003 & $(0.28)$ \\
\hline & $\alpha_{3}$ & $0.0044 * * *$ & $(2.58)$ & $0.0042 * * *$ & $(2.72)$ & $0.0039 * * *$ & $(2.86)$ & $0.0037 * * *(2.80)$ & $0.0031 * *$ & $(2.54)$ & 0.0011 & $(1.32)$ \\
\hline & $\alpha_{5}$ & $0.0049 * * *$ & $(2.93)$ & $0.0049 * * *$ & $(3.25)$ & $0.0049 * * *$ & $(3.85)$ & $0.0050 * * *(4.45)$ & $0.0045 * * *$ & $(4.36)$ & $0.0017 * *$ & $(2.10)$ \\
\hline & $\alpha_{6}$ & $0.0049 * * *$ & $(2.89)$ & $0.0050 * * *$ & $(3.16)$ & $0.0056^{* * *}$ & $(4.14)$ & $0.0061 * * *(5.22)$ & $0.0062 * * *$ & $(6.02)$ & $0.0028 * * *$ & $(3.24)$ \\
\hline
\end{tabular}

Note: This table provides the abnormal returns $\left(\boldsymbol{\alpha}_{\boldsymbol{C}}, \boldsymbol{\alpha}_{3}, \boldsymbol{\alpha}_{5}\right.$, and $\left.\boldsymbol{\alpha}_{\mathbf{6}}\right)$ of each zero-cost portfolio using realized skewness constructed in business cycle expansions after controlling for common risk factors over different $(E)$ estimation and holding $(H)$ periods from January 1970 to December 2019. Newey-West adjusted $t$-statistics are in parentheses. *,**, and *** denote significance at the $10 \%, 5 \%$, and $1 \%$ levels respectively. 
Table VII. Realized skewness and subsequent returns formed on equal-weighted industry returns

\begin{tabular}{|c|c|c|c|c|c|c|c|c|c|c|c|c|c|}
\hline E & & 1 & & 3 & & 6 & & 9 & & 12 & & 24 & \\
\hline 1 & $\mathrm{H}-\mathrm{L}$ & 0.556 & (1.63) & $0.438^{*}$ & (1.93) & $0.375 * *$ & $(2.31)$ & $0.347 * * *$ & $(2.72)$ & $0.338 * * *$ & $(3.12)$ & $0.171 * *$ & $(2.24)$ \\
\hline & $\alpha_{C}$ & $0.0059 * * *$ & $(4.10)$ & $0.0050 * * *$ & $(5.96)$ & $0.0042 * * *$ & (6.96) & $0.0036 * * *$ & $(5.95)$ & $0.0036 * * *$ & $(6.14)$ & $0.0017 * * *$ & $(3.86)$ \\
\hline & $\alpha_{3}$ & $0.0058 * * *$ & $(3.78)$ & $0.0051 * * *$ & $(5.67)$ & $0.0041 * * *$ & $(6.36)$ & $0.0033 * * *$ & $(5.38)$ & $0.0031 * * *$ & $(5.60)$ & $0.0012 * * *$ & $(3.06)$ \\
\hline & $\alpha_{5}$ & $0.0052 * * *$ & $(3.09)$ & $0.0049 * * *$ & $(5.01)$ & $0.0047 * * *$ & $(6.06)$ & $0.0039 * * *$ & $(5.29)$ & $0.0034 * * *$ & $(4.67)$ & $0.0012 * *$ & $(2.21)$ \\
\hline & $\alpha_{6}$ & $0.0052 * * *$ & $(3.07)$ & $0.0049 * * *$ & $(5.06)$ & $0.0046^{* * *}$ & $(5.87)$ & $0.0039 * * *$ & $(4.96)$ & $0.0034 * * *$ & $(4.47)$ & $0.0013^{* *}$ & $(2.27)$ \\
\hline 3 & $\mathrm{H}-\mathrm{L}$ & 0.504 & $(1.46)$ & $0.500 * *$ & $(2.24)$ & $0.421 * * *$ & $(2.67)$ & $0.427 * * *$ & $(3.44)$ & $0.391 * * *$ & $(3.67)$ & $0.199 * * *$ & $(2.62)$ \\
\hline & $\alpha_{C}$ & $0.0058 * * *$ & $(4.23)$ & $0.0058 * * *$ & $(5.41)$ & $0.0050 * * *$ & $(6.51)$ & $0.0045 * * *$ & $(6.29)$ & $0.0042 * * *$ & $(6.39)$ & $0.0018 * * *$ & $(3.11)$ \\
\hline & $\alpha_{3}$ & $0.0055^{* * *}$ & $(3.72)$ & $0.0056^{* * *}$ & $(4.60)$ & $0.0046^{* * *}$ & $(5.59)$ & $0.0039 * * *$ & $(5.84)$ & $0.0036 * * *$ & $(5.63)$ & $0.0011 * *$ & $(2.07)$ \\
\hline & $\alpha_{5}$ & $0.0046^{* * *}$ & $(2.78)$ & $0.0049 * * *$ & $(3.83)$ & $0.0045 * * *$ & $(4.95)$ & $0.0042 * * *$ & $(5.03)$ & $0.0038 * * *$ & $(4.80)$ & 0.0011 & (1.61) \\
\hline & $\alpha_{6}$ & $0.0049 * * *$ & $(2.91)$ & $0.0053 * * *$ & $(4.15)$ & $0.0047 * * *$ & $(5.16)$ & $0.0043 * * *$ & $(5.12)$ & $0.0040 * * *$ & $(5.02)$ & $0.0013 *$ & $(1.85)$ \\
\hline 6 & $\mathrm{H}-\mathrm{L}$ & $0.620^{*}$ & $(1.83)$ & $0.519 * *$ & $(2.35)$ & $0.499 * * *$ & $(3.17)$ & $0.497 * * *$ & $(4.02)$ & $0.428 * * *$ & $(4.0)$ & $0.250 * * *$ & $(3.24)$ \\
\hline & $\alpha_{C}$ & $0.0070 * * *$ & $(5.05)$ & $0.0062 * * *$ & $(5.52)$ & $0.0058 * * *$ & $(6.03)$ & $0.0056 * * *$ & $(6.08)$ & $0.0049 * * *$ & $(5.83)$ & $0.0024 * * *$ & $(3.09)$ \\
\hline & $\alpha_{3}$ & $0.0068 * * *$ & $(4.57)$ & $0.0059 * * *$ & $(4.94)$ & $0.0053 * * *$ & $(5.78)$ & $0.0050 * * *$ & $(5.89)$ & $0.0041 * * *$ & $(5.31)$ & $0.0014 *$ & $(1.84)$ \\
\hline & $\alpha_{5}$ & $0.0062 * * *$ & $(3.52)$ & $0.0056^{* * *}$ & $(4.21)$ & $0.0052 * * *$ & $(4.86)$ & $0.0055 * * *$ & $(5.17)$ & $0.0041 * * *$ & (3.98) & 0.0014 & $(1.36)$ \\
\hline & $\alpha_{6}$ & $0.0063 * * *$ & $(3.55)$ & $0.0059 * * *$ & $(4.41)$ & $0.0053 * * *$ & $(4.91)$ & $0.0055^{* * *}$ & $(5.27)$ & $0.0043 * * *$ & $(4.20)$ & 0.0016 & $(1.59)$ \\
\hline 9 & $\mathrm{H}-\mathrm{L}$ & $0.636^{*}$ & (1.89) & $0.593 * * *$ & $(2.71)$ & $0.570 * * *$ & (3.66) & $0.496 * * *$ & $(4.03)$ & $0.417 * * *$ & $(3.88)$ & $0.256^{* * *}$ & $(3.27)$ \\
\hline & $\alpha_{C}$ & $0.0072 * * *$ & (4.99) & $0.0069 * * *$ & $(5.59)$ & $0.0067 * * *$ & $(6.18)$ & $0.0057 * * *$ & $(5.54)$ & $0.0050 * * *$ & $(5.09)$ & $0.0025 * * *$ & $(2.63)$ \\
\hline & $\alpha_{3}$ & $0.0068 * * *$ & $(4.57)$ & $0.0064 * * *$ & $(5.15)$ & $0.0059 * * *$ & $(5.93)$ & $0.0047 * * *$ & $(5.13)$ & $0.0039 * * *$ & $(4.41)$ & 0.0010 & $(1.07)$ \\
\hline & $\alpha_{5}$ & $0.0062 * * *$ & $(3.52)$ & $0.0061 * * *$ & $(4.27)$ & $0.0057 * * *$ & $(4.53)$ & $0.0051 * * *$ & $(4.20)$ & $0.0040 * * *$ & $(3.18)$ & 0.0012 & $(0.90)$ \\
\hline & $\alpha_{6}$ & $0.0063 * * *$ & $(3.59)$ & $0.0063 * * *$ & $(4.41)$ & $0.0058 * * *$ & $(4.58)$ & $0.0053 * * *$ & $(4.37)$ & $0.0044 * * *$ & $(3.52)$ & 0.0016 & $(1.20)$ \\
\hline 12 & $\mathrm{H}-\mathrm{L}$ & $0.756^{* *}$ & $(2.22)$ & $0.607 * * *$ & $(2.81)$ & $0.511 * * *$ & (3.29) & $0.443 * * *$ & $(3.58)$ & $0.371 * * *$ & $(3.44)$ & $0.231 * * *$ & $(2.91)$ \\
\hline & $\alpha_{C}$ & $0.0083 * * *$ & $(5.74)$ & $0.0070 * * *$ & $(5.67)$ & $0.0061 * * *$ & $(5.40)$ & $0.0053 * * *$ & (4.89) & $0.0045 * * *$ & (4.17) & $0.0023 * *$ & $(2.40)$ \\
\hline & $\alpha_{3}$ & $0.0079 * * *$ & $(5.41)$ & $0.0065^{* * *}$ & $(5.38)$ & $0.0051 * * *$ & $(5.02)$ & $0.0043 * * *$ & $(4.42)$ & $0.0034 * * *$ & $(3.48)$ & 0.0009 & $(0.83)$ \\
\hline & $\alpha_{5}$ & $0.0072 * * *$ & $(4.47)$ & $0.0060 * * *$ & $(4.34)$ & $0.0049 * * *$ & $(4.03)$ & $0.0044 * * *$ & $(3.29)$ & $0.0035^{* *}$ & $(2.51)$ & 0.0011 & $(0.69)$ \\
\hline & $\alpha_{6}$ & $0.0074 * * *$ & $(4.53)$ & $0.0062^{* * *}$ & $(4.52)$ & $0.0051 * * *$ & $(4.12)$ & $0.0047 * * *$ & $(3.51)$ & $0.0038 * * *$ & $(2.82)$ & 0.0014 & $(0.95)$ \\
\hline 24 & H-L & 0.364 & $(1.08)$ & 0.326 & $(1.50)$ & $0.279^{*}$ & $(1.76)$ & $0.249 * *$ & $(1.96)$ & $0.221 * *$ & $(2.0)$ & 0.124 & $(1.56)$ \\
\hline & $\alpha_{C}$ & $0.0045^{* * *}$ & $(3.44)$ & $0.0043 * * *$ & $(3.49)$ & $0.0038 * * *$ & (3.18) & $0.0034 * * *$ & $(3.05)$ & $0.0030 * * *$ & $(2.87)$ & $0.0016^{*}$ & $(1.90)$ \\
\hline & $\alpha_{3}$ & $0.0039 * * *$ & $(3.07)$ & $0.0036 * * *$ & $(2.97)$ & $0.0028 * *$ & $(2.35)$ & $0.0024 * *$ & $(2.03)$ & $0.0020^{*}$ & $(1.65)$ & 0.0006 & $(0.49)$ \\
\hline & $\alpha_{5}$ & $0.0028 * *$ & $(2.14)$ & $0.0021 *$ & $(1.73)$ & 0.0016 & $(1.20)$ & 0.0012 & $(0.91)$ & 0.0008 & $(0.56)$ & -0.0003 & $(-0.24)$ \\
\hline & $\alpha_{6}$ & $0.0031 * *$ & $(2.39)$ & $0.0024^{*}$ & $(1.94)$ & 0.0017 & $(1.35)$ & 0.0016 & $(1.19)$ & 0.0012 & $(0.87)$ & 0.0001 & $(0.06)$ \\
\hline
\end{tabular}

Note: This table provides the equal-weighted excess returns (\%) and abnormal returns $\left(\boldsymbol{\alpha}_{\boldsymbol{C}}, \boldsymbol{\alpha}_{\mathbf{3}}, \boldsymbol{\alpha}_{\mathbf{5}}\right.$, and $\left.\boldsymbol{\alpha}_{\mathbf{6}}\right)$ for the zero-cost portfolio formed on realized skewness calculated by using equal-weighted industry returns over the selected estimation $(E)$ and holding periods $(H)$ from January 1970 to December 2019 . Newey-West adjusted $t$-statistics are in parentheses. *,**, and *** denote significance at the $10 \%, 5 \%$, and $1 \%$ levels, respectively. 